Article

\title{
Exploring the Diversity of Fungal DyPs in Mangrove Soils to Produce and Characterize Novel Biocatalysts
}

\author{
Amal Ben Ayed ${ }^{1,2}$, Geoffroy Saint-Genis ${ }^{3}$, Laurent Vallon ${ }^{3}$, Dolores Linde ${ }^{4} \oplus$, Annick Turbé-Doan ${ }^{1}$, \\ Mireille Haon ${ }^{1}$, Marianne Daou ${ }^{1,9}{ }^{\mathbb{D}}$, Emmanuel Bertrand ${ }^{1} \mathbb{D}$, Craig B. Faulds ${ }^{1}$, Giuliano Sciara ${ }^{1}$, \\ Martino Adamo ${ }^{3,5}$, Roland Marmeisse ${ }^{3,5}$, Sophie Comtet-Marre ${ }^{6}$, Pierre Peyret ${ }^{6}$, Danis Abrouk ${ }^{3}$, \\ Francisco J. Ruiz-Dueñas ${ }^{4}\left(\mathbb{D}\right.$, Cyril Marchand ${ }^{7,8}$, Mylène Hugoni ${ }^{3}$, Patricia Luis ${ }^{3}$, Tahar Mechichi ${ }^{2} \mathbb{B}$ \\ and Eric Record $1, * \mathbb{B}$
}

check for

updates

Citation: Ben Ayed, A.; Saint-Genis, G.; Vallon, L.; Linde, D.; Turbé-Doan, A.; Haon, M.; Daou, M.; Bertrand, E.; Faulds, C.B.; Sciara, G.; et al. Exploring the Diversity of Fungal DyPs in Mangrove Soils to Produce and Characterize Novel Biocatalysts. J. Fungi 2021, 7, 321. https://doi.org/ $10.3390 /$ jof7050321

Academic Editor: Laurent Dufossé

Received: 26 March 2021

Accepted: 16 April 2021

Published: 21 April 2021

Publisher's Note: MDPI stays neutral with regard to jurisdictional claims in published maps and institutional affiliations.

Copyright: (c) 2021 by the authors. Licensee MDPI, Basel, Switzerland. This article is an open access article distributed under the terms and conditions of the Creative Commons Attribution (CC BY) license (https:// creativecommons.org/licenses/by/ $4.0 /)$.
1 INRAE, UMR1163, Biodiversité et Biotechnologie Fongiques, Aix-Marseille Université, 13288 Marseille, France; amal.benayed@enis.tn (A.B.A.); annick.doan@univ-amu.fr (A.T.-D.); mireille.haon@inrae.fr (M.H.); mariane.daou@ku.ac.ae (M.D.); emmanuel.bertrand@univ-amu.fr (E.B.); craig.faulds@univ-amu.fr (C.B.F.); giuliano.sciara@inrae.fr (G.S.)

2 Laboratoire de Biochimie et de Génie, Enzymatique des Lipases, Université de Sfax, Ecole Nationale d'Ingénieurs de Sfax, 3038 Sfax, Tunisia; tahar.mechichi@enis.rnu.tn

3 Université Lyon, Université Claude Bernard Lyon 1, CNRS, INRAE, VetAgro Sup, UMR Ecologie Microbienne, 69622 Villeurbanne, France; geoffroy.saint-denis@univ-lyon1.fr (G.S.-G.); laurent.valon@univ-lyon1.fr (L.V.); martino.adamo@univ-lyon1.fr (M.A.); patricia.luis@univ-lyon1.fr (P.L.); roland.marmeisse@univ-lyon1.fr (R.M.); danis.abrouk@univ-lyon1.fr (D.A.); mylene.hugoni@univ-lyon1.fr (M.H.)

4 Centro de Investigaciones Biológicas Margarita Salas (CIB), CSIC, 28040 Madrid, Spain; lolalinde@cib.csic.es (D.L.); fjruiz@cib.csic.es (F.J.R.-D.)

5 Dipartimento di Scienze della Vita e Biologia dei Sistemi, Università degli Studi di Torino, 10125 Torino, Italy

6 Université Clermont Auvergne, INRAE, MEDiS, 63000 Clermont-Ferrand, France; sophie.comtet-marre@inrae.fr (S.C.-M.); pierre.peyret@inrae.fr (P.P.)

7 IMPMC, Institut de Recherche Pour le Développement (IRD), UPMC, CNRS, MNHN, 98851 Noumea, France cyril.marchand@unc.nc

8 ISEA, EA, Université de la Nouvelle-Calédonie (UNC), 3325, BP R4, 98851 Noumea, France

9 Department of Chemistry, Khalifa University, P.O. Box 127788, Abu Dhabi, United Arab Emirates

* Correspondence: eric.record@inrae.fr

Abstract: The functional diversity of the New Caledonian mangrove sediments was examined, observing the distribution of fungal dye-decolorizing peroxidases (DyPs), together with the complete biochemical characterization of the main DyP. Using a functional metabarcoding approach, the diversity of expressed genes encoding fungal DyPs was investigated in surface and deeper sediments, collected beneath either Avicennia marina or Rhizophora stylosa trees, during either the wet or the dry seasons. The highest DyP diversity was observed in surface sediments beneath the $R$. stylosa area during the wet season, and one particular operational functional unit (OFU1) was detected as the most abundant DyP isoform. This OFU was found in all sediment samples, representing $51-100 \%$ of the total DyP-encoding sequences in $70 \%$ of the samples. The complete cDNA sequence corresponding to this abundant DyP (OFU 1) was retrieved by gene capture, cloned, and heterologously expressed in Pichia pastoris. The recombinant enzyme, called DyP1, was purified and characterized, leading to the description of its physical-chemical properties, its ability to oxidize diverse phenolic substrates, and its potential to decolorize textile dyes; DyP1 was more active at low $\mathrm{pH}$, though moderately stable over a wide $\mathrm{pH}$ range. The enzyme was very stable at temperatures up to $50{ }^{\circ} \mathrm{C}$, retaining $60 \%$ activity after $180 \mathrm{~min}$ incubation. Its ability to decolorize industrial dyes was also tested on Reactive Blue 19, Acid Black, Disperse Blue 79, and Reactive Black 5. The effect of hydrogen peroxide and sea salt on DyP1 activity was studied and compared to what is reported for previously characterized enzymes from terrestrial and marine-derived fungi.

Keywords: lignocellulose degrading enzymes; dye-decolorizing peroxidases; heterologous expression; dye decolorization; marine fungus; mangrove; salt adaptation 


\section{Introduction}

Coastal mangrove soils are fascinating ecosystems, representing a whole forest environment at the interface between land and sea. These ecosystems consist mainly of woody plants that grow under extreme environmental conditions such as high salinity and high temperature [1]. Mangrove leaves and sediments contain a high concentration of carbonaceous material, feeding a considerable bacterial and fungal microflora [2,3]. According to Latha [4], mangrove fungi represent the second largest ecological group of all marine fungi. Recently, the structure of microbial communities in New Caledonian mangrove sediments was analyzed in detail using a metabarcoding approach [3]. This work investigated the distribution of prokaryotic and fungal communities with respect to depth, vegetation cover, and season. The prokaryotic community appeared to be exclusively shaped by sediment depth, with resulting differences in prokaryotic phyla composition. On the contrary, the fungal community was evenly distributed according to the above criteria and showed a dominance of Ascomycota over Basidiomycota in all analyzed layers [3]. Mangroves are considered to be the largest carbon reservoir in coastal ecosystems and actively supply carbon to adjacent ecosystems [5,6]. In this carbon-rich environment, mangrove fungi play a key role in the recycling of organic matter, including Lignocellulose-rich biomass [7]. In terrestrial forests, fungal degradation of plant lignocellulose is based on a close association with the woody material, and on the secretion of a complex and variable cocktail of enzymes acting in a sequential, sometimes synergistic way [8,9]. Lignocellulolytic enzymes, including cellulases, hemicellulases, and lignin-degrading enzymes (including Ligninolytic peroxidases and laccases), are classified in the CAZy database [10]. The scientific literature related to their characterization is broad and diverse for enzymes derived from terrestrial species. By contrast, very little is known about the enzymatic mechanisms employed by mangrove-derived fungi to break down plant biomass and their adaptation to marine conditions, especially to high salt concentrations. In a previous study, we showed that the presence of sea salt modified the composition of secreted lignocellulolytic enzymes, with increased secretion of xylanases and cellulases, and lower production of oxidoreductases belonging to the auxiliary activities (AA) class of the CAZy database [11]. This tendency was recently confirmed in the study of the marine-derived fungus Stemphylium lucomagnoense [12]. Although terrestrial basidiomycetes, particularly white-rot fungi, are seen as the key actors in environmental lignin degradation, marine-derived ascomycetes were also demonstrated to significantly degrade lignin [13]. For example, the mangrove fungus Pestalotiopsis sp. was demonstrated to produce two different laccases that are active, with different enzymatic behavior, in up to $5 \%$ sea salt [14]. Similarly, the marine white-rot basidiomycete Phlebia sp. was shown to secrete two enzymatically different manganese peroxidases (MnPs), in saline and non-saline conditions, respectively, also illustrating the adaptation of marine fungi to sea salt [15].

Classical ligninolytic heme peroxidases, including manganese peroxidases (MnPs), lignin peroxidases (LiPs), and versatile peroxidases (VPs), belong to the peroxidase-catalase superfamily [16]. Dye-decolorizing peroxidases (DyPs) are heme peroxidases that were more recently described. They belong, together with chloride dismutases (Cld) and other heme-binding proteins (EfeB gene), to the "dimeric $\alpha+\beta$ barrel structural superfamily" (Pfam CL0032, SCOP identifier 54909), also called CDE superfamily [17,18]. However, the evolutionary relationships among the $\mathrm{CDE}$ family members are not clear: they show low identity in structure-based alignments, and their common folding could represent a convergent or divergent evolutionary process [19]. The fold of these proteins consists of a $\beta$ barrel decorated with $\alpha$ helices, resulting from homo- or hetero-dimerization of two ferredoxin-like motifs [20]. Each motif is supplied by distinct polypeptide chains, like in some cofactor-free bacterial enzymes [21,22], or by the $N$ and $C$ terminal domains of a single polypeptide, like in DyPs, each containing a conserved histidine in the hemebinding site and a GXXDG signature motif. This sequence contains the catalytic aspartate that acts as a proton acceptor, playing the role of the catalytic histidine found in plant peroxidases [23,24]. DyPs are produced in bacteria [25] as well as in filamentous fungi, with 
many examples in basidiomycetes such as Bjerkandera adusta [26], Pleurotus ostreatus [27], Auricularia auricula-judae [28,29], and Trametes versicolor [30]. They have been purified and biochemically characterized, demonstrating their capacities to oxidize a large variety of substrates, such as phenolic compounds (2, 6-dimethoxyphenol and guaiacol) and nonphenolic compounds (veratryl alcohol and $\mathrm{Mn}^{2+}$ ), together with anthraquinone substrates and also flavonoids extracted from oak wood (catechin and quercetin) [30,31]. While heme peroxidases have been largely studied in fungi isolated from terrestrial environments, little is known about their involvement in lignocellulose degradation in marine habitats. In comparison, other ligninolytic enzymes, such as laccases isolated from marine-derived fungi, have already been isolated, produced, and characterized [32,33], and some have been shown to participate in lignocellulose breakdown [34] or be promising candidates for biotechnological processes such as dye decolorization $[33,35]$.

In the present work, a cDNA capture by hybridization approach was used (i) to evaluate the diversity of expressed fungal genes that encode DyPs in mangrove sediments, using a metabarcoding approach, and (ii) to recover and clone full-length DyP cDNAs in P. pastoris, to gain insights into the biochemical properties of enzymes isolated from marine environments. One DyP, called DyP1 in this study, was heterologously expressed and characterized, and its biotechnological potential for dye decolorization was assessed.

\section{Materials and Methods}

\subsection{Strains for Cloning and Heterologous Expression}

Escherichia coli strain DH5 $\alpha$ (Promega, Charbonnieres, France) was used for vector storage and propagation. P. pastoris strain X33 (Invitrogen, Carlsbad, CA, USA) was used for the heterologous expression of the DyP-encoding synthetic cDNA after optimization of codons (GenScript, Piscataway, NJ, USA).

\subsection{Sediment Sampling, RNA Extraction, and cDNA Synthesis}

Sediment samples were collected from a mangrove wetland located in Saint Vincent Bay $\left(21^{\circ} 55^{\prime} 58^{\prime \prime} \mathrm{S}, 166^{\circ} 4^{\prime} 30^{\prime \prime} \mathrm{E}\right)$ on the west coast of New Caledonia. As previously described [3], sediment samples were collected in three independent $10 \mathrm{~m}^{2}$ plots (A, B, and C) located $50 \mathrm{~m}$ apart and defined in Avicennia marina (A) and Rhizophora stylosa (R) pristine areas. Three sediment cores (50 $\mathrm{cm}$ deep) were collected in 2016 at low tide with a stainlesssteel corer $\left(8 \mathrm{~cm}\right.$ diameter) in each $10 \mathrm{~m}^{2}$ plot during the wet (March) and dry (November) seasons. Oxic ( $0-10 \mathrm{~cm}$ deep) and anoxic (40-50 cm deep) fractions were collected from each core, and a single composite sample per fraction and per plot $(\mathrm{A}, \mathrm{B}$, or $\mathrm{C})$ for each tree area (A. marina and R. stylosa) was prepared by mixing equal amounts of sediments. Per season (March or November), a total of 12 different composite samples were thus obtained and separately analyzed: (i) R1A, R1B, and R1C and R2A, R2B, and R2C corresponding, respectively, to the oxic and anoxic fractions from the three plots $(\mathrm{A}, \mathrm{B}$, and $\mathrm{C})$ designated in the R. stylosa area (R). (ii) $\mathrm{A} 1 \mathrm{~A}, \mathrm{~A} 1 \mathrm{~B}$, and $\mathrm{A} 1 \mathrm{C}$ and $\mathrm{A} 2 \mathrm{~A}, \mathrm{~A} 2 \mathrm{~B}$, and $\mathrm{A} 2 \mathrm{C}$ corresponding, respectively, to oxic and anoxic fractions of the three plots $(\mathrm{A}, \mathrm{B}$, or $\mathrm{C})$ localized in the $A$. marina area (A). All composite samples were frozen and kept at $-70{ }^{\circ} \mathrm{C}$ until use.

Total RNA was extracted from 8-12 $\mathrm{g}$ of each composite sample using the RNeasy PowerSoil Total RNA kit according to the manufacturer's recommendations (Qiagen, Germantown, MD, USA). RNA quality was evaluated on $1 \%$ agarose gels and the absence of DNA contamination confirmed by PCR using non-reverse transcribed mRNA and eukaryotic constitutively expressed EF1 $\alpha$ gene-specific primers [36]. Specific reverse transcription of poly-A mRNA, followed by double-stranded cDNA synthesis and amplification, was performed on 500 ng of total RNA using the Mint-2 cDNA synthesis kit (Evrogen, Moscow, Russia). The optimal number of PCR cycles to maintain a balance between transcript representation and nonspecific background amplification during the cDNA amplification was estimated to be 27 cycles. The resulting cDNAs, previously purified using a phenolchloroform protocol [37], were used as templates to specifically capture by hybridization and sequence expressed fungal genes encoding DyPs. 
2.3. Probe Design, cDNA Capture by Hybridization, and High-Throughput Sequencing of Fungal DyP cDNA

First, 1267 publicly available fungal DyP DNA coding sequences were identified by BLAST searches and collected from GenBank (http:/ / www.ncbi.nlm.nih.gov/genbank/, accessed on 19 April 2021), the Joint Genome Institute Mycocosm database (https:// mycocosm.jgi.doe.gov/mycocosm/home, http:/ /www.ncbi.nlm.nih.gov/genbank/, accessed on 19 April 2021; [38]) and the specialized RedOxiBase (http:/ / peroxibase.toulouse. inra.fr/, accessed on 19 April 2021; [39]). This sequence data set was used to design 69 (70 bp long) degenerate capture probes using the KASpOD software (https:/ /g2im. u-clermont1.fr/kaspod/index.php, accessed on 19 April 2021); [40] (individual probe sequences will be published in a separate paper on fungal DyP diversity). In silico, individual probes could hybridize to $0.2-11 \%$ of the 1267 fungal DyP sequences (four allowed mismatches). Oligonucleotides were synthesized as single-strand DNA flanked by two adaptor sequences (ATCGCACCAGCGTGT and CACTGCGGCTCCTCA) for their PCR amplification and conversion to biotinylated RNA probes using the T7 RNA polymerase.

cDNA capture by hybridization was carried out as described by Bragalini et al. (2014) [41]. Briefly, $2 \mu \mathrm{g}$ of heat-denatured PCR-amplified cDNAs was hybridized to the equimolar mix of biotinylated RNA probes $(500 \mathrm{ng})$ for $24 \mathrm{~h}$ at $65^{\circ} \mathrm{C}$. Probe/cDNA hybrids were captured on streptavidin-coated paramagnetic beads (Dynabeads ${ }^{\circledR} \mathrm{M}-280$ Streptavidin, Invitrogen). After different washing steps to remove unbound cDNAs, the captured cDNAs were eluted using $50 \mu \mathrm{L}$ of $0.1 \mathrm{M} \mathrm{NaOH}$ at room temperature, neutralized with $70 \mu \mathrm{L}$ of $1 \mathrm{M}$ Tris- $\mathrm{HCl}(\mathrm{pH}$ 7.5), and purified using the MinElute PCR purification kit (Qiagen). Captured cDNAs were amplified using the primer M1 (Mint-2 cDNA synthesis kit, Evrogen) that binds at both $5^{\prime}$ and $3^{\prime}$ ends of the cDNAs. PCR amplifications were performed in $50 \mu \mathrm{L}$ reaction mixtures containing $5 \mu \mathrm{L}$ of captured cDNA, $200 \mu \mathrm{M}$ of dNTPs, $400 \mathrm{nM}$ of primer M1, $5 \mu \mathrm{L}$ of 10X Encyclo buffer, and $1 \mu \mathrm{L}$ of 50X Encyclo DNA polymerase (Evrogen). Cycling conditions were $1 \mathrm{~min}$ at $95^{\circ} \mathrm{C}$ followed by 25 cycles of $15 \mathrm{~s}$ at $95^{\circ} \mathrm{C}, 20 \mathrm{~s}$ at $66^{\circ} \mathrm{C}$, and $3 \mathrm{~min}$ at $72{ }^{\circ} \mathrm{C}$. Ten independent amplifications were conducted for each sample. PCR products of the same sample were purified using the MinElute PCR purification kit (Qiagen, Courtaboeuf, France) and pooled. A second round of hybridization and PCR amplification was performed using each of the amplified cDNA samples obtained after the first hybridization capture.

Captured cDNAs of each sediment sample (12 per season) were used as templates to specifically amplify fragments of expressed fungal DyP genes using the following fungal-specific tagged degenerate primers: DyP-F, 5'-Tag-TGYCCITTYGCIGCNCAYAT-3' and DyP-R, 5'-Tag-RAARAARTAYTCICCNCC-3' (Table S1; [42]. All PCR amplifications were performed in triplicates in $25 \mu \mathrm{L}$ reaction mixtures containing $20 \mathrm{ng}$ of amplified cDNA, $2.5 \mu \mathrm{L}$ of 10X polymerase buffer (Invitrogen), $0.75 \mu \mathrm{L}$ of $\mathrm{MgCl}_{2}(50 \mathrm{mM}), 2.5 \mu \mathrm{L}$ of dNTPs ( $2 \mathrm{mM}$ each), $1 \mu \mathrm{L}$ of each primer ( $20 \mu \mathrm{M}$, Invitrogen), $0.3 \mu \mathrm{L}$ of BSA $\left(20 \mathrm{mg} \mathrm{mL}^{-1}\right)$, and $0.1 \mu \mathrm{L}$ of Taq DNA polymerase (5U. $\mu \mathrm{L}^{-1}$, Invitrogen). Cycling conditions were 3 min at $94{ }^{\circ} \mathrm{C}$ and 35 cycles of $45 \mathrm{~s}$ at $94{ }^{\circ} \mathrm{C}, 45 \mathrm{~s}$ at $50{ }^{\circ} \mathrm{C}$, and $45 \mathrm{~s}$ at $72{ }^{\circ} \mathrm{C}$, followed by $10 \mathrm{~min}$ at $72{ }^{\circ} \mathrm{C}$. Control reactions without nucleic acid were systematically run in parallel. Amplicons from the three independent PCR reactions were pooled and purified using the Agencourt AMPure XP Kit (Beckman Coulter Diagnostics, California, CA, USA) and quantified by fluorometry using a Qubit 2.0 fluorimeter and the Qubit dsDNA HS assay kit (Invitrogen, ThermoFisher Scientific, Waltham, MA, USA). Per season (March or November), an equimolar mix of the tagged PCR products obtained for the 12 different sediment samples was prepared and sequenced by FASTERIS (FASTERIS, Plan-les-Ouates, Switzerland) on an Illumina MiSeq sequencer $(2 \times 250 \mathrm{bp})$.

In parallel, four full-length-captured cDNA composite samples corresponding to the oxic and anoxic fractions collected in the A. marina (A1, A2) and R. stylosa (R1, R2) areas were generated by pooling an equal amount of captured cDNAs obtained for the different sediment samples of each season. These four full-length captured cDNA samples were 
sequenced using the Illumina HiSeq $20002 \times 250$ bp technology (I.G.A. Technologies, Udine, Italy).

\subsection{Bioinformatic Analysis and Statistics}

Concerning the Miseq raw data, fungal DyP paired-end reads were merged using Pear [43] and demultiplexed. Denoising procedures consisted of discarding reads that fell outside the expected length range (expected size 350-470 bp) and those containing ambiguous bases $(\mathrm{N})$. Sequences were clustered into operational functional units (OFUs) using SWARM [44]. SWARM is a de novo clustering based on an unsupervised singlelinkage clustering method that reduces the impact of clustering parameters on the resulting OFUs by avoiding arbitrary global clustering thresholds and input sequence ordering dependencies. SWARM builds OFUs in two steps: (i) an initial set of OFUs was constructed by iteratively agglomerating similar amplicons, and (ii) amplicon abundance values were used to reveal OFUs internal structures and to break them up into sub-OFUs if necessary. In the present work, the SWARM aggregation distance equaled to 3. Chimeras were removed using VSEARCH [45], and low abundance sequences accounting for less than $0.005 \%$ of the dataset were filtered out. This whole procedure was performed using the pipeline FROGS [46]. To be able to compare samples, a normalization procedure was applied to randomly resample down to 32,556 sequences per sample. A Wilcoxon test was used to statistically evaluate the differences between the alpha diversity indices calculated (Shannon index $\left(\mathrm{H}^{\prime}\right)$, complement of the Simpson index (1-D), and Evenness $\left(J^{\prime}\right)$ ). The effect of environmental factors (tree, season, and depth) on the composition of expressed fungal genes encoding DyPs were tested using nonparametric permutationbased multivariate analysis of variance (PERMANOVA, adonis function; [47] based on abundance dissimilarity (Bray-Curtis) matrices). These analyses were performed using the VEGAN package (http://cran.r-project.org, accessed on 19 April 2021) in R. The sequence data generated in this study were deposited in the EMBL-ENA public database (PRJEB43346 for the first sampling campaign (March) dataset and PRJEB43343 for the second sampling campaign (November) dataset).

Concerning the HiSeq raw data for full-length cDNA reconstruction through gene capture by hybridization enrichment, adapter sequences were eliminated using Cutadapt [48]. Sequence quality was evaluated with Trimmomatic [49]; bases with quality lower than 20 were eliminated and only sequences longer than 60 bases were kept. Trimmed sequences were then assembled using IDBA-UD [50] (default parameters) and resulting contigs were further assembled with CAP3 [51] (default parameters) to obtain longer contigs. A similarity search between a custom peroxidase database and contigs was performed using DIAMOND [52], with the BLASTx command in "sensitive" mode (i.e., a maximal $E$-value of $1 \times 10^{-5}$ and a minimal identity of $50 \%$ ). Matching sequences were further analyzed to search the DYP peroxidase domain using ScanProSite [53] and the Prosite database [54].

The ProtParam tool (http:/ / web.expasy.org/protparam/, accessed on 19 April 2021) was used to predict the theoretical pI, molecular mass, and molar extinction coefficient of DyP. For sequence comparison, BlastP was used to search for sequences with similarity to DyP1 in the UniProtKB/Swiss-Prot database (http: / / www.uniprot.org/blast, accessed on 19 April 2021). The search parameters were scoring matrix BLOSUM 62, gapped alignment allowed, and cut-off $E$-value 0.1. DyP1 was aligned with $241 \mathrm{DyP}$ sequences identified in Agaricomycotina genomes available at the MycoCosm portal (https:/ / mycocosm.jgi. doe.gov/mycocosm/home, accessed on 19 April 2021) and GenBank using MUSCLE as implemented in MEGA X (https://www.megasoftware.net/, accessed on 19 April 2021) [55]. A maximum likelihood phylogenetic tree was then constructed by MEGA $X$ using the WAG evolutionary model with gamma-distributed rate variation and the amino acid frequencies of the dataset. 


\subsection{Cloning and Expression of DyP-encoding cDNA}

DyP1 was produced using the in-house 3PE Platform (P. pastoris Protein Express: www. platform3pe.com/, accessed on 19 April 2021). The cDNA encoding DyP was synthesized after codon optimization for P. pastoris (GeneArt, Regensburg, Germany) and inserted into the vector $\mathrm{pPICZ} \alpha \mathrm{A}$ (Invitrogen, Cergy-Pontoise, France) using XhoI and XbaI restriction sites in frame adding a C-terminal (His)6-tag to the recombinant protein.

P. pastoris strain $\mathrm{X} 33$ and the $\mathrm{pPICZ} \alpha \mathrm{A}$ vector are components of the P. pastoris Easy Select Expression System (Invitrogen). The PmeI-linearized pPICZ $\alpha$ A recombinant plasmid was inserted into P. pastoris competent cells by electroporation. Zeocin-resistant transformants were then screened for protein production.

\subsection{Production and Purification of Recombinant DyP}

The best producing transformant was grown in $2.5 \mathrm{~L}$ of BMGY $\left(10 \mathrm{~g} \mathrm{~L}^{-1}\right.$ glycerol, $10 \mathrm{~g} \mathrm{~L}^{-1}$ yeast extract, $20 \mathrm{~g} \mathrm{~L}^{-1}$ peptone, $3.4 \mathrm{~g} \mathrm{~L}^{-1} \mathrm{YNB}, 10 \mathrm{~g} \mathrm{~L}^{-1}$ ammonium sulfate, $100 \mathrm{mM}$ phosphate buffer $\mathrm{pH} 6$, and $0.2 \mathrm{~g} \mathrm{~L}^{-1}$ of biotin) in flasks shaken at $30{ }^{\circ} \mathrm{C}$ in an orbital shaker $(200 \mathrm{rpm})$ for $16 \mathrm{~h}$ to an OD600 of 2-6. Expression was induced by transferring the cells into $500 \mathrm{~mL}$ of BMMY $\left(10 \mathrm{~g} \mathrm{~L}^{-1}\right.$ yeast extract, $20 \mathrm{~g} \mathrm{~L}^{-1}$ peptone, $3.4 \mathrm{~g} \mathrm{~L}^{-1} \mathrm{YNB}, 10 \mathrm{~g} \mathrm{~L}^{-1}$ ammonium sulfate, $100 \mathrm{mM}$ phosphate buffer $\mathrm{pH} 6$, and $0.2 \mathrm{~g} \mathrm{~L}^{-1}$ of biotin) adding 0.1 or $0.5 \mathrm{gL}^{-1}$ of hemin at $20^{\circ} \mathrm{C}$ in an orbital shaker (200 rpm) for a further three days. Each day the medium was supplemented with $3 \%(v / v)$ methanol.

The supernatant was collected after harvesting cells by centrifugation at $3500 \times g$ for $5 \mathrm{~min}$ at $4{ }^{\circ} \mathrm{C}$. After adjusting the $\mathrm{pH}$ to 7.8 , the supernatant was filtered on $0.45 \mu \mathrm{m}$ filters (Millipore, Molsheim, France) and loaded onto $5 \mathrm{~mL}$ HisTrap HP columns (GE healthcare, Buc, France) connected to an Akta Xpress system (GE Healthcare). Prior to loading, the column was equilibrated with buffer A Tris- $\mathrm{HCl} 50 \mathrm{mM} \mathrm{pH} \mathrm{7.8,} \mathrm{NaCl}$ $150 \mathrm{mM}$, and imidazole $10 \mathrm{mM}$. The (His)6-tagged recombinant enzyme was eluted with buffer B Tris- $\mathrm{HCl} 50 \mathrm{mM} \mathrm{pH} \mathrm{7.8,} \mathrm{NaCl} 150 \mathrm{mM}$, and imidazole $500 \mathrm{mM}$. The fractions eluted containing the purified protein were pooled, concentrated with a $10 \mathrm{kDa}$ vivaspin concentrator unit (Sartorius, Plaiseau, France), and dialyzed against $50 \mathrm{mM}$ sodium acetate buffer $\mathrm{pH}$ 5.2.

Protein concentration was determined using a Nanodrop ND-2000 spectrophotometer (Thermo Fisher Scientific, IL, USA) by adsorption at $280 \mathrm{~nm}$ with theoretical molecular masses and molar extinction coefficients calculated from protein sequence using Expasy tools. A fraction of eluate was loaded onto 10\% Tris-glycine precast SDS-PAGE (Bio-Rad, Marnes-la-Coquette, France) to check protein purity and integrity. The molecular mass under denaturing conditions was determined with PageRuler Prestained Protein Ladder (Thermo Fisher Scientific, IL, USA)

\subsection{Structural Analysis}

A 3D model of the DyP1 was obtained from the automated protein structure homologymodeling server SWISS-MODEL [56] using the crystal structure of B. adusta DyP (PDB $3 \mathrm{MM} 3$ ) as a template. The electrostatic surface was computed using the default parameters in PyMol. The putative glycosylation sites were predicted using NetOGlyc 4.0 Server [57].

\subsection{Standard Conditions for Peroxidase Activity}

DyP activity was estimated from the absorbance changes observed during substrate oxidation at optimal $\mathrm{pH}$ values at $30{ }^{\circ} \mathrm{C}$ in a Uvikon XS spectrophotometer (BioTek Instruments, Colmar, France) [29]. Hydrogen peroxide $(0.25 \mathrm{mM})$ was added to initiate the reaction. Oxidation of 2,2'-azino-bis(3-ethylbenzothiazoline-6-sulfonic acid (ABTS) was followed by generation of its cation radical $\left(\varepsilon_{436}=29.3 \mathrm{mM}^{-1} \mathrm{~cm}^{-1}\right)$. RB19 oxidation was monitored for colorant disappearance $\left(\varepsilon_{595}=10 \mathrm{mM}^{-1} \mathrm{~cm}^{-1}\right)$. Substrate oxidation was determined by measuring the enzymatic activity using saturating concentrations of RB19 $(600 \mu \mathrm{M})$ and ABTS $(5 \mathrm{mM})$ in $100 \mathrm{mM}$ of citrate-phosphate buffer. 


\subsection{Influence of Temperature and $p H$ on DyP Activity and Enzyme Stability}

To determine optimal temperature, the purified $\mathrm{DyP}$ was assayed over the temperature range of $20-70{ }^{\circ} \mathrm{C}$ in standard conditions. For the $\mathrm{pH}$ profiles, DyP activity was determined in $100 \mathrm{mM}$ of citrate-phosphate buffer range from $\mathrm{pH} 2.6$ to 7 using ABTS and RB19 as substrates at $30^{\circ} \mathrm{C}$.

To define the thermal stability, DyP aliquots were incubated at different temperatures $\left(30-70{ }^{\circ} \mathrm{C}\right)$ for $30,60,90,120$, and $180 \mathrm{~min}$. Thermal inactivation was stopped by immediately cooling the treated protein aliquot on ice, and activity was measured under standard conditions. The $\mathrm{pH}$ stability was determined by incubating DyP in $10 \mathrm{mM}$ citratephosphate buffer at different $\mathrm{pH}\left(2.6,3,4,5\right.$, and 6) for 4,24 , and $48 \mathrm{~h}$ at $30^{\circ} \mathrm{C}$, and then assaying the activity in standard conditions for each substrate.

\subsection{Effect of Hydrogen Peroxide and Sea Salt on DyP Activity}

The effects of $\mathrm{H}_{2} \mathrm{O}_{2}$ on peroxidase activity were determined under standard assay conditions at the optimal $\mathrm{pH}$ in the range of 0.1 to $5 \mathrm{mM}$ in $0.1 \mathrm{M}$ citrate-phosphate buffer at $30^{\circ} \mathrm{C}$.

The influence of sea salt on DyP activity was measured spectrophotometrically in standard assay conditions, as described above, after sea salt addition (1-5\% wt/vol) using DyP of Trametes versicolor as a control [30].

\subsection{Substrate Specificity and Kinetics}

To determine the best substrates of the enzyme, enzymatic activities were measured using a UVIKONxs spectrophotometer (Bio-TEK Instruments) at optimal $\mathrm{pH}$ at $30^{\circ} \mathrm{C}$ by following the oxidation of different substrates. For ABTS, 2,6-dimethoxyphenol (DMP) and veratryl acohol (VA) oxidation, absorbance increases at 436 (radical cation; $\varepsilon_{436}=29.3 \mathrm{mM}^{-1} \mathrm{~cm}^{-1}$ ), 496 (dimeric coerulignone; $\varepsilon_{469}=55 \mathrm{mM}^{-1} \mathrm{~cm}^{-1}$ ), and $310 \mathrm{~nm}$ (veratraldehyde; $\varepsilon_{310}=9.3 \mathrm{mM}^{-1} \mathrm{~cm}^{-1}$ ) were followed, respectively. Absorbance decreases were followed in the case of Reactive Blue 19 (RB19) (595 nm, $\varepsilon_{595}=10 \mathrm{mM}^{-1} \mathrm{~cm}^{-1}$ ) oxidation resulting in dye decolorization. The oxidation of $\mathrm{Mn}^{2+}$ was determined at $238 \mathrm{~nm}$ $\left(\mathrm{Mn}^{3+}\right.$-tartrate complex; $\left.\varepsilon_{238}=6.5 \mathrm{mM}^{-1} \mathrm{~cm}^{-1}\right)$ in $100 \mathrm{mM}$ tartrate buffer $\mathrm{pH} 4$.

All enzymatic activities were measured in linear increments (decreases for RB19). The Michaelis constant, $K_{\mathrm{m}}$, together with the enzyme turnover value, $k_{\mathrm{cat}}$, were obtained by non-linear least squares fitting of the experimental measurements to the Michaelis-Menten model. Fitting of these constants to the normalized equation $v=\left(k_{\text {cat }} / K_{\mathrm{m}}\right)[S] /\left(1+[S] / K_{\mathrm{m}}\right)$ yielded the catalytic efficiency values $\left(k_{\mathrm{cat}} / K_{\mathrm{m}}\right)$ with their corresponding standard errors.

\subsection{Decolorization Properties}

Five synthetic dyes, Acid Black (AB) (560 nm; 0.005\% vol/vol), RB5 (610 nm; 0.0025\% vol/vol), Disperse Blue 79 (DB79) (530 nm; 0.0005\% vol/vol), Basic Blue 41 (BB41) (610 nm; $0.00001 \% \mathrm{vol} / \mathrm{vol})$, and Vat Green (VG) $(640 \mathrm{~nm} ; 0.00025 \% \mathrm{vol} / \mathrm{vol})$, were supplied by SETAS (Çerkezköy, Turkey) and used for determining the decolorization properties of $\mathrm{DyP}$ at $37^{\circ} \mathrm{C}$. The reaction mixture contained DyP $\left(0.125 \mathrm{mg} \mathrm{mL}^{-1}\right)$, dye solutions (final concentration described above), citrate-phosphate buffer (100 mM, pH 3), and $0.25 \mathrm{mM}$ of $\mathrm{H}_{2} \mathrm{O}_{2}$ in a total volume of $1 \mathrm{~mL}$. The enzymatic dye decolorization was detected by measuring the decrease in color absorbance in $1 \mathrm{~h}$. The percentage of decolorization efficiency was calculated as follows:

$$
\text { Decolorization }(\%)=\left(\left(A_{\mathrm{i}}-A_{t}\right) / A_{\mathrm{i}}\right) \times 100
$$

where $A_{\mathrm{i}}$ is the initial absorbance of a dye, and $A_{t}$ is the absorbance of the dye after each time point $t$. 


\section{Results}

\subsection{Diversity and Capture of Fungal DyP Encoding cDNAs}

The diversity of expressed genes encoding fungal DyPs was investigated in surface and deeper mangrove sediments beneath A. marina and R. stylosa trees during the wet (March) and dry (November) seasons. Sediment samples were collected in three independent plots (A, B, and C) in the A. marina (A) and R. stylosa (R) pristine areas. This expressed gene diversity was evaluated using a metabarcoding approach (Illumina Miseq) on environmental cDNAs previously enriched in DyP sequences by gene capture by hybridization. The normalized DyP dataset consisted of 781,344 sequences distributed among 25 different operational functional units (OFUs), corresponding to 25 putative DyP encoding cDNAs (Table S2). The number of OFUs per sediment sample varied from one to 10. DyP diversity, estimated with the Shannon index, was systematically higher in the surface layers during the wet season (Figure 1; Supplementary Table S2). The highest DyP diversity was observed for the surface layers beneath the R. stylosa area during the wet season. By contrast, the DyP diversity was systematically lower in the surface layers during the dry season (Figure 1A; Table S3).
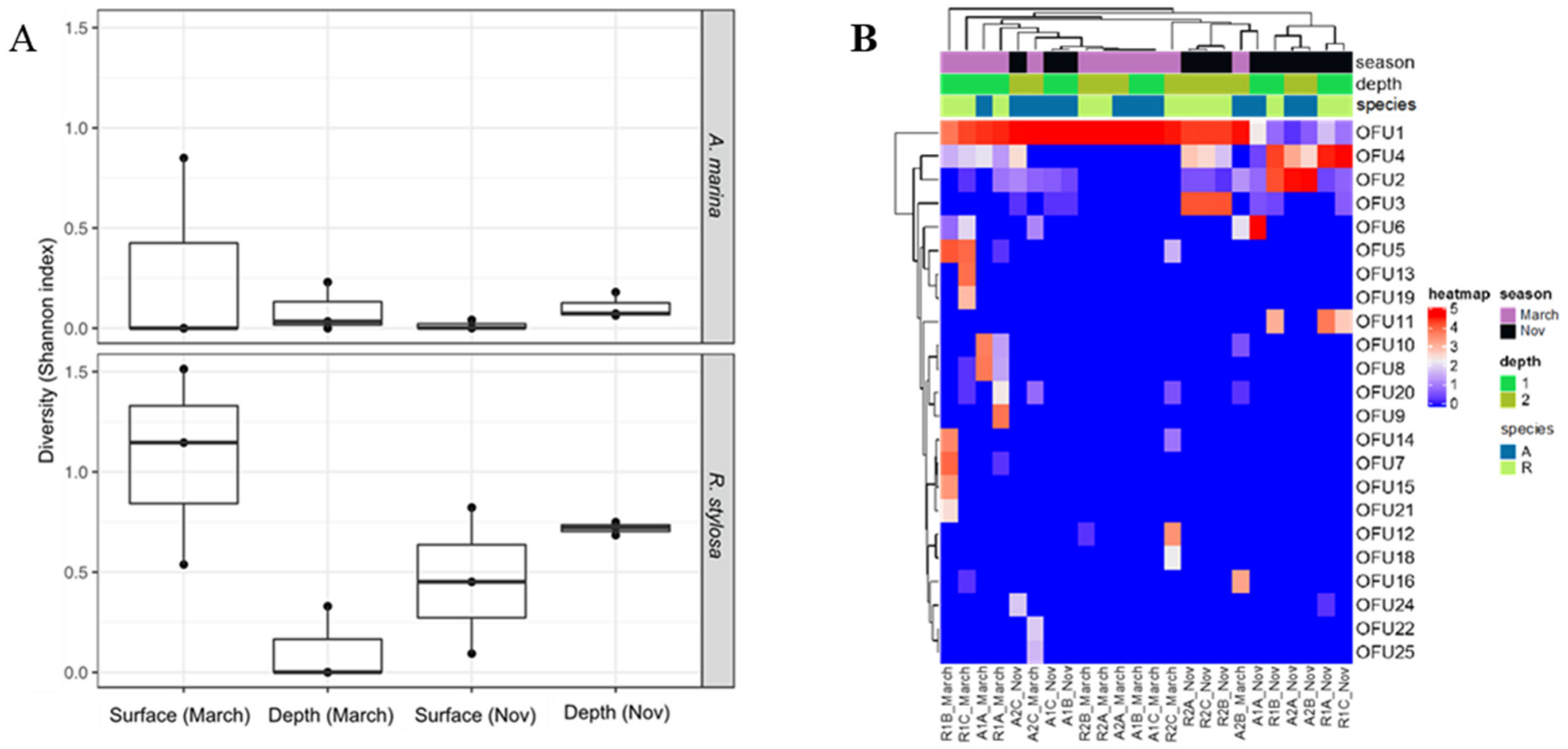

Figure 1. Diversity of expressed genes encoding fungal DyPs in surface and deeper sediments collected beneath two tree species (Avicennia marina and Rhizophora stylosa) during the wet (March) and dry (November) seasons. (A) Diversity estimated with the Shannon index and (B) distribution of the different Operational Functional Units (OFUs).

Regarding the distribution of OFUs, the most abundant one (OFU1) was detected in all sediment samples and represented $51,100 \%$ of all sequences in $70 \%$ of the samples (Figure 1B). The full-length cDNA sequence of OFU1 was obtained from the HiSeq dataset after gene capture by hybridization enrichment. The difference in the composition of expressed DyP-genes assessed through a nonparametric multivariate analysis of variance (PERMANOVA) highlighted a strong seasonal effect $\left(\mathrm{P}=5.8 \times 10^{-5}, \mathrm{R}^{2}=0.178\right.$; Table 1$)$. Tree species $\left(P=0.032, R^{2}=0.062\right)$ and sediment depth $\left(P=0.021, R^{2}=0.072\right)$ had a lower impact on the composition of the expressed fungal genes (Table 1 ). 
Table 1. Effect of environmental factors on the composition of expressed fungal genes encoding dye-decolorizing peroxidases (DyPs).

\begin{tabular}{ccccc}
\hline & Df & $\mathbf{F}$ & $\mathbf{P}$ & $\mathbf{R}^{\mathbf{2}}$ \\
\hline Variable & & & & \\
Tree species & 1 & 3.011 & 0.032 & 0.062 \\
Sediment depth & 1 & 3.453 & 0.021 & 0.072 \\
Season & 1 & 8.579 & $5.8 \times 10^{-5}$ & 0.178 \\
Interaction & & & & \\
Tree $\times$ Depth & 1 & 6.789 & $7.1 \times 10^{-4}$ & 0.141 \\
Tree $\times$ Season & 1 & 2.462 & 0.062 & 0.051 \\
Depth $\times$ Season & 1 & 2.926 & 0.036 & 0.061 \\
Tree $\times$ Depth $\times$ & 1 & 4.946 & 0.005 & 0.102 \\
Season & 16 & & & \\
Residuals & & &
\end{tabular}

The differences between groups were tested using PERMANOVA analysis on Bray-Curtis dissimilarity matrices. Abbreviations: Df: degrees of freedom; F: F-test statistic.

\subsection{Phylogenetic Analysis}

We decided to study the most widely represented peroxidase in mangrove soils, OFU1, which we called DyP1. A BlastP search was conducted against the UniProtKB/SwissProt database using DyP1 as the query. As a result, DyP sequences from fungal species of the orders Auriculariales, Sebacinales, and Geastrales, included in the subphylum Agaricomycotina, emerged as the proteins with the highest amino acid sequence identities to DyP1 (Table 2).

Table 2. DyPs deposited from the UniProtKB/Swiss-Prot database presenting the highest amino acid sequence identities (47-59\%) with DyP1 from mangrove soils (the number of residue pairs considered for each comparison is shown in brackets). The DyP entry names of 12 enzymes are indicated together with the fungal species they belong to, from the orders Auriculariales (Exidia glandulosa and A. auricula-judae), Sebacinales (Piriformospora indica and Serendipita vermifera), and Geastrales (Sphaerobolus stellatus).

\begin{tabular}{cc}
\hline & DyP1 \\
\hline E. glandulosa DyP A0A165BX62 & $59 \%(459)$ \\
P. indica DyP G4TL25 & $57 \%(460)$ \\
E. glandulosa DyP A0A165FCE7 & $56 \%(460)$ \\
E. glandulosa DyP A0A165G2C1 & $54 \%(498)$ \\
E. glandulosa DyP A0A165GZG2 & $54 \%(469)$ \\
S. stellatus DyP A0A0C9U2H4 & $54 \%(465)$ \\
S. vermifera DyP A0A0C3B0S6 & $53 \%(460)$ \\
E. glandulosa DyP A0A166ARP7 & $52 \%(505)$ \\
A. auricula-judae DyPI2DBY1 & $51 \%(505)$ \\
S. stellatus DyP A0A0C9UT91 & $51 \%(505)$ \\
S. stellatus DyP A0A0C9VF44 & $49 \%(472)$ \\
S. stellatus DyP A0A0C9VPJ8 & $47 \%(506)$ \\
\hline
\end{tabular}

DyP1 then underwent a phylogenetic analysis with 241 DyP sequences from 88 fungal species belonging to 15 orders of this subphylum available at the JGI-DOE MycoCosm portal [38] and GenBank. Sequences within the resulting phylogram (Figure 2) can be sorted into the seven evolutionary clusters previously described by Linde et al. (2015a) [20]. Cluster I and III are the best defined and include most of the protein sequences. Cluster III mainly comprises sequences from Agaricales and Polyporales, with different enzymes characterized such as DyP4 from P. ostreatus [58], DyP1 from T. versicolor [30], and DyP from Coriolopsis trogii [59], and a hypothetical DyP cloned from Ganoderma lucidum [60] (blue arrows in Figure 2). Cluster I also includes Agaricales and Polyporales sequences, but here we can also find sequences from the orders Auriculariales, Sebacinales, and Geastrales, 
which are not represented in the rest of the clusters, and include eight characterized fungal DyPs from B. adusta [61], Termitomyces albuminosus (UniProtKB/Swiss-Prot Q8NKF3) [62], A. auricula-judae [28], Mycetinis scorodonius (two enzymes) [63,64], Polyporaceae sp. [65], $P$. ostreatus [58], and Pleurotus sapidus [66]. The sequence of DyP1 that we obtained from mangrove soils lies within Cluster I, flanked by Auriculariales and Sebacinales sequences, suggesting that the fungal species producing this enzyme most likely belongs to one of these two orders.

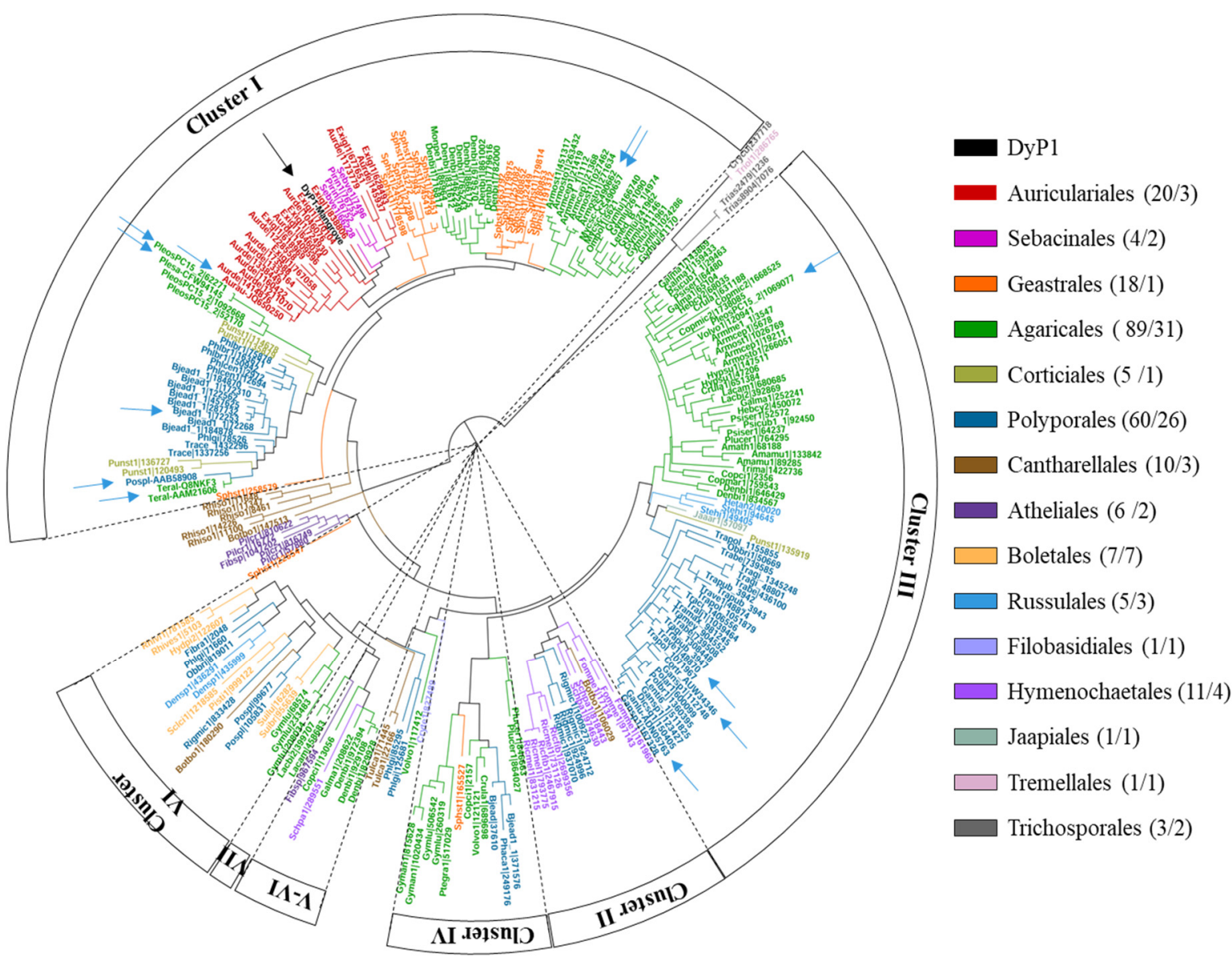

Figure 2. Maximum likelihood phylogenetic tree, constructed with 1000 bootstrap replications, showing the position of DyP1 from mangrove (black arrow) with respect to 233 DyP sequences identified in 82 published (and a few unpublished) Agaricomycotina genomes (the latter with permission of the PIs project) available at the JGI Mycocosm Portal on May 2020, including sequences of Pleurotus ostreatus (JGI 1069077 and JGI 62271), Bjerkandera adusta (JGI 72253), and Trametes versicolor (JGI 48870). Eight GenBank sequences from Auricularia auricula-judae (Aurau-JQ650250), Mycetinis scorodonius (MycscCS490657 and Mycsc-CS490662), Ganoderma lucidum (Ganlu-ADN05763), Polyporaceae sp. (Pospl-AAB58908), Termitomyces albuminosus (Teral-AAM21606), Pleurotus sapidus (Plesa-CFW94145), and Coriolopsis trogii (Cortr_AUW34346) are also included. The color of both branches and enzymes indicates the order of the fungal species they belong to according to the legend, where the total DyP cDNA number is shown (including eight from GenBank) followed by the number of genomes for each order. The positions of the characterized DyPs from A. auricula-judae, B. adusta, Polyporaceae sp. (Irpex lacteus), M. scorodonius, T. albuminosus, P. ostreatus, T. versicolor, P. sapidus, and C. trogii are indicated with blue arrows.

An alignment with five characterized fungal DyPs (Figure 3) representative of Clusters I and III confirmed that DyP1 presented the key amino acid residues characteristic of this peroxidase family, including (i) distal arginine and aspartate residues (Arg371 and Asp213), the latter forming part of the DyP signature motif GXXDG, necessary for enzyme activation by $\mathrm{H}_{2} \mathrm{O}_{2}$ [61], and (ii) the proximal histidine (His351) occupying the fifth coordination position of the heme iron, and a second aspartate (Asp433) [67]. Interestingly, some surface 
aromatic residues putatively involved in catalysis were also identified in the amino acid sequence of DyP1, as described in more detail below.

\begin{tabular}{|c|c|c|}
\hline DYP1 & MLISPLFLAAAISSLRVASADGSALVARQGTELPGPLTDPRVTSMLADIPGFGPLPNVTD & 40 \\
\hline Aurau_JQ650250 & MRLSPVFVALLS-GLLAADLGLARSVAPRVADSPAAVTGTRKTSLLKNVAGLPPVPSAAQ & -2 \\
\hline Mycsc_-490657 & $\overline{M R L--T Y L P L F A-G I A I Q S A----C A F P N F S-K S S I L K P R R T N S L L I N P D A Q P D L P T A K Q ~}$ & -3 \\
\hline Bjead_72253 & $\begin{array}{l}\text { MRLSLFVVSVAV }---L V G S-\cdots--- \text { SSHVNAAKLGARQTRTTPLLTNFPGQAPLPALIQ } \\
\end{array}$ & -6 \\
\hline Pleos_1069077 & 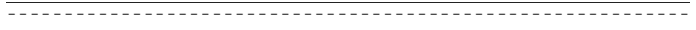 & \\
\hline Trave_48870 & 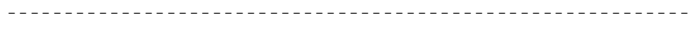 & \\
\hline DyP1 & ---- -VVTNATLPVDDIQADILVGMRKKKERFYFFKIN-NATLFKAGLHNTVVAEITSVK & 94 \\
\hline Aurau_JQ650250 & - - - - -VAATSLNTDDIQGDILVGMHKQKQLFYFFAIN-DPATFKTHLASDIAPVVASVT & 51 \\
\hline Mycsc_-490657 & 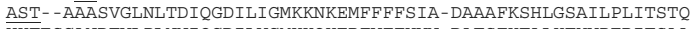 & \\
\hline Bjead_72253 & HKTESGANDTVLPLNNIQGDILVGMKKQKERFVFFHVN-DATSFKTALKTYVPERITSAA & 53 \\
\hline Pleos_1069077 & - - - MTTPAPPLDLNNIQGDILGGLPKRTETYFFFDVT -NVDQFKANMAHFI PHI KTSAG & 55 \\
\hline \multirow[t]{2}{*}{ Trave_48870 } & - - - -MSSTVPAFDPANVQGDILVGLPKKAQQY I I FQIDDNVTGGRKALNNLI I PLITTTTQ & \\
\hline & 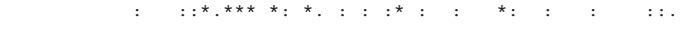 & \\
\hline DYP1 & KIL- & \\
\hline Aurau_JQ650250 & QLS - - - NVATQPLVALNIAFSNTGLLALGVT-DNLGDSLFANGQAK & \\
\hline Mycsc_-490657 & QLL- - AVASQPTTAVNLAFSQTGLNALGLAAQGLGDSLFASGQFS & \\
\hline Bjead_72253 & ILI- - - - SDPSQQPLAFVNLGFSNTGLQALGIT-DDLGDAQFPDGQFA & \\
\hline Pleos_1069077 & I I KDREA I KEHK - - - - -RQKKPGLVPMAAVNVSFSHLGLQKLGIT - DDLSDNAFTTGQRK & \\
\hline \multirow{2}{*}{ Trave_48870 } & VQQDRTKIANNKKAAKEQGTPALIKLSGVNVAFSQAGLTKLGIT - DDLLDPAFKEGQLA & \\
\hline & $\quad \quad: *: . * *: * * \quad * *:: \ldots * * \quad * \quad * *$ & \\
\hline DYP1 & DANFLGDPGT-1-1--NGWEPTFVATSSLHGVILLASDTTTLIDTQVAHLEAVWG- -1 & \\
\hline Aurau_JQ650250 & DATSFKE-ST- - - - - - SSWVPQFAG - TG IHGVI ILASDTTDLIDQQVASIESTFG - - - & \\
\hline Mycsc_-490657 & GAQSLGDPGT - - - - - - SNWVQAFAG - TGIHGVFLLASDTVDNVNAELSQIQSILG- - - - & \\
\hline Bjead_-72253 & DAANLGD - DL- - - - - GQWVAPFTG - TTIHGVFLIGSDQDDFLDQFTDDISSTFG - - - & \\
\hline Pleos_1069077 & DAEILGDPGSKNGDAFTPAWEAPFLK--DIHGVIFVAGDCHGSVNKKLDEI KHI FGVGTS & \\
\hline \multirow[t]{2}{*}{ Trave_48870 } & DAQNLGDPGSTASGKFVPDWLPAFLQ - GNIHGVILI I GDCNATIAETRVVIERIFSVGAS & \\
\hline & $. *:: . \quad * \quad * \quad: * * *::: \ldots * \quad: \quad:$ : & \\
\hline DyP1 & -SSITKLYELQGAIRPGAEEGHEMF FYK G IAQPAVFGFNLVPYPGQLAVPAGIILTGEA & \\
\hline Aurau_JQ650250 & - SSISKL YSLSASIRPGNEAGHEMF FFL I AQPAINGFNT - PLPGQNIVDAGVIITGAT & \\
\hline Mycsc-490657 & - TSITEAYRLQGEARPGDQQGHEHF GFM I SNPAIDGFST-ALPGQAVLSPGLFLLGED & \\
\hline Bjead-72253 & -ASITQVQALSGSARPGDQAGHEHF FFL E I SQPSVTGWETTVFPGQAVVPPGI ILTGRD & \\
\hline Pleos_1069077 & HASISEVTHVRGDVRPGDVHAHEHF GFL I SNPAVEQFDQNPLPGQDPIRPGFILAKEN & \\
\hline \multirow[t]{2}{*}{ Trave_48870 } & NATLHEVTTLIGKVRPGLEDGHEHF GFL I SQPAIEGIDTNPNPGQETVRQGI ILLGRD & \\
\hline & 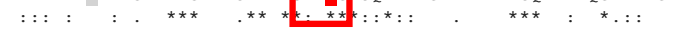 & \\
\hline DYP1 & GD - -TVTRPSWTKDGSFMAFRKLRQYVPEFNNFVVSNAPPVA- - -NKTTAESIAIFGSRL & \\
\hline Aurau_JQ650250 & ND- - PITRPSWAVGGSFLAFRQLEQLVPEFNKYLLDNAPAGS- - -GS-LQARADLLGARM & \\
\hline Mycsc_-490657 & GDGSSSSRPSWAKDGSFLAFRQLQRVPEFNKFLADNAALT- & \\
\hline Bjead_72253 & GD - -TGTRPSWALDGSFMAFRHFQQKVPEFNAYTLANAI PANSAGNLTQQEGAELLGARM & \\
\hline & GDSRAAARPDWAKDGSFLTFRYLFQMVPEFDDFLESNPIVLP- - - GLSRKEGSELLGARI & \\
\hline \multirow{2}{*}{ Trave_48870 } & GDG-TTGRPSWAIDGSFLALRYLFQLVPEFNNFLKGNALTGN - - GLTPDQGSELLGARL & \\
\hline & ${ }^{*} \quad * * . *: . * *::: *: * * * * *:: \quad * \quad:: *: *$ & \\
\hline DYP1 & VGRWKSGAPIDKTPLVDDPVMAADPYQNNNFDFFHLLSNFTSDQSHCPFAA/IRKTRPRD & \\
\hline Aurau_JQ650250 & VGRWKSGAPIDLTPTADDPALGADAQRNNNFTYSHAGFDLGSDQSHCPFSA I IRKTRPRA & \\
\hline Mycsc_490657 & MGRWKSGAPVDLAPTADDVDLANDPQRNNNFNFTHAGFTETTDETHCPFSAHIRKTNPRS & \\
\hline Bjead_72253 & FGRWKSGAPIDLAPTADDPALGADPQRNNNFDYSDT - - - - LTDETRCPFGAHVRKTNPRQ & \\
\hline Pleos 1069077 & VGRWKSGAPIEITPLKDDPKLAADAQRNNKFDFGDS - -LVRGDQTKCPFAAAIRKTYPRN & \\
\hline \multirow[t]{2}{*}{ Trave_48870 } & MGRWKSGAPIDLAPTQDDPALGADASRNNNFRYAFT - -DDQTTTIRCPFAAHTRKTNPRA & \\
\hline & $. * * * * * * *:: \quad: * \quad * * \quad: . * \quad: * *: * \quad: \quad: * * * * * * * * * *$ & \\
\hline DyP1 & DLPT- - - - -GALNTIMRAGIPȲGPEPSNSELTNGA- - - TTQDRGLAFVAYQSQIAQ & \\
\hline Aurau_JQ650250 & DLGGSLTPPNLSAGANSIMRSGI PYGPEVTSAESASNTT - - - TQERGLAFVAYQAQLSQ & \\
\hline Mycsc_490657 & DFNPQ - - - - - NTNNHI IRAGI YYGPEVTDAEASSNTSSTDASLERGLAFVAYQSNIGN & \\
\hline Bjead_72253 & DLGGP - - - - - - -VDTFHAMRSS I PYGPETSDAELASGVT - - - - AQDRGLLFVEYQSI IGN & \\
\hline Pleos_1069077 & DLEGP - - PLKADIDNRRI IRRG IQFGPEVTSQEHHDKKT - - - -HHGRGLLFVCYSSSIDD & \\
\hline \multirow[t]{2}{*}{ Trave_48870 } & DLEDP - - PISFSTETRRI IRRGVQFGDEVTPQEAASGKT- - - - ALDRGLIFAAYQSTIPN & \\
\hline & 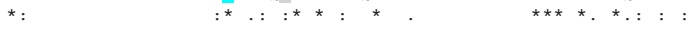 & \\
\hline DyP1 & 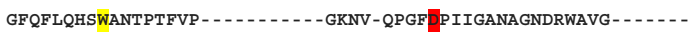 & \\
\hline Aurau_JQ650250 & GFHFLQQTWADNANFPP $-\ldots$ & \\
\hline Mycsc_-490657 & GFAFLQQAWVDNANFFF- - - & \\
\hline Bjead_72253 & 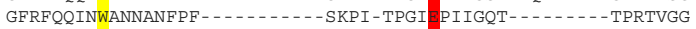 & \\
\hline \multirow{3}{*}{$\begin{array}{l}\text { Pleos_1069077 } \\
\text { Trave_48870 }\end{array}$} & GFHFIQESWANAPNFPVNAVTSAGPIPPLDGV-VPGF AI IGQKVG- - - - -GGIRQISG & \\
\hline & GFQFIQKSWANTVSFPP - ........-NKPF-TPGF PIIGQTND - . - - DSVRTLAG & \\
\hline & $* * * * * .: \quad . *$ & \\
\hline DYF & TGNLTF - - PVFIKSNGGEYFFVPSISAIRDTLSV- & \\
\hline JQ650250 & LLPSNSSASLSI - PQFVVSHGGEYFFSPPISAIGGRLSA $-\cdots$ & \\
\hline Mycsc_490657 & LDPTDSTKIVTIN-TDFVSSRGGEYFFSPSLSAIQNTLSV- - - - - - 455 & \\
\hline Bjead_72253 & LDPLNQNETFTV- - PLFVIPKGGEYFFLPSISALTSTIAA- & \\
\hline Pleos_1069077 & TNPNDPTTNITLPDQDFVVPRGGEYFFSPSITALKTKFAIGVASPAPHSQAPISA 504 & \\
\hline Trave 48870 & TDPNNQTAELSLP - TDWVLPKGGEYFFSPSIPALRTKFALAA & \\
\hline
\end{tabular}

Figure 3. Alignment of DyP1 and five characterized DyPs from Cluster I (Aurau_JQ650250, Mycsc_490657, and Bjead_72253) and III (Pleos_1069077 and Trave_48870). Highlighted residues include (i) proximal histidine (magenta) and aspartate (red); (ii) distal-side arginine (cyan) and aspartate (red), the latter within the GXXDG signature motif (red box); and (iii) four solvent-exposed aromatic residues, corresponding to two conserved tryptophans (yellow), as well as two tyrosines (green) sometimes substituted by other amino acids (gray). Alignment was produced with Clustal2.1, and symbols below the sequences indicate full conservation of the same (asterisk) or equivalent residues (colon) and partial residue conservation (dot).

\subsection{Structural Analysis}

A DyP1 structural model was generated by homology modeling (Swiss Model). An analysis of this model revealed a ferredoxin-like fold with an internal heme cofactor acces- 
sible from the solvent through a narrow channel (Figure 4A,B). No significant differences were observed in size when the heme access channel was compared with that of the $A$. auricula-judae DyP (AauDyP) (Figure 4D) where this enzyme could oxidize different substrates [20]. Different key residues identified in the amino acid sequence (Figure 3) are located at positions of the molecular architecture typical of a catalytically active enzyme (Figure 4C). The sequence includes six tryptophans and nine tyrosines with some of them (Tyr68, Trp149, Tyr192, Tyr228, Tyr268, Tyr325, Tyr376, Trp416, and Trp445) exposed to the solvent. The oxidation of bulky and high redox potential substrates at surface aromatic residues, via long-range electron transfer pathways to the heme, is known in ligninolytic peroxidases and DyPs $[61,68]$. Among the above aromatic residues, Trp149 and Trp416 are conserved in the five characterized DyPs shown in Figure 3. Trp416 occupies the same position of the catalytic Trp377 in the A. auricula-judae DyP [61] (Figure 4D) and of Trp411 (the only solvent-exposed aromatic residue) in the T. versicolor DyP (Figure 4E), pointing to a putative catalytic role of this residue in DyP1 (and also in T. versicolor DyP).

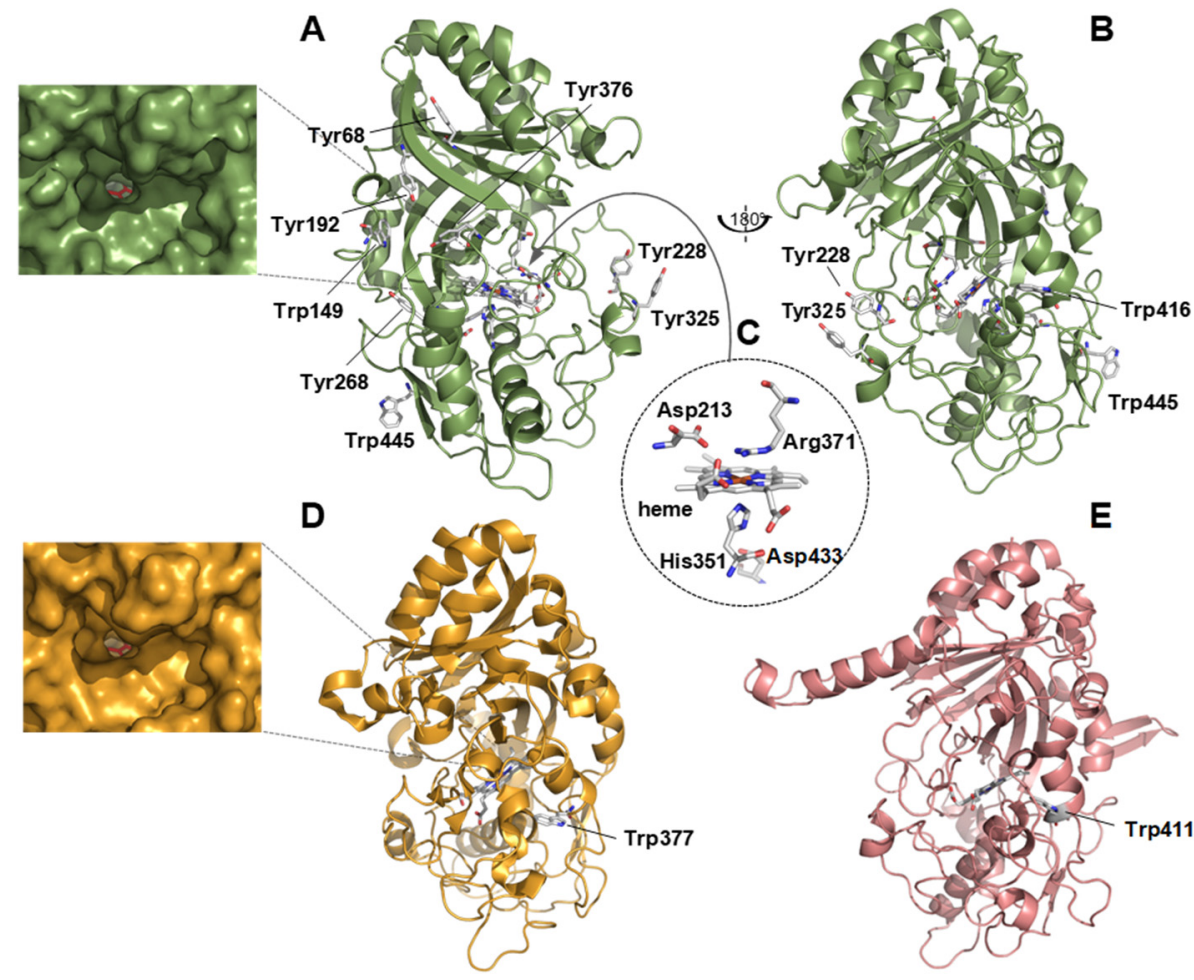

Figure 4. Homology model of DyP1 from mangrove soils, with a typical ferredoxin-like fold, showing the location of Trp and Tyr residues exposed to the solvent in two different orientations of the protein (A,B); and the heme environment amino acid residues Asp213, Arg371, His351, and Asp433 (as a structural detail in (C)). Trp416 in (B) is located at a position equivalent to that of the catalytic Trp377 in the A. auricula-judae DyP (AauDyP) crystal structure (PDB: 4W7J) (D); and of Trp411 in a homology model of T. versicolor DyP (JGI 48870) (E). A detail of the heme access channel region in DyP1 and AauDyP is also shown in A and D (the heme cofactor is depicted as red sticks at the bottom of the channel).

\subsection{Heterologous Production and Purification of the Recombinant DyP1}

After the transformation of P. pastoris with the recombinant vector $\mathrm{PPICZ} \alpha$-A containing the DyP1 encoding cDNA, 48 transformants were selected for their resistance to zeocin and were then screened for the presence of DyP1 in the extracellular medium. The best transformant was selected based on the band intensity corresponding to the recombinant protein and visualized following SDS-PAGE (expected molecular weight for DyP1 was $55 \mathrm{kDa})$. 
As dye-peroxidases are heme enzymes, the heme precursor hemin was added to Pichia cultures at two different concentrations $\left(0.1\right.$ and $\left.0.5 \mathrm{~g} \mathrm{~L}^{-1}\right)$, to favor the production of functional holo-DyP1. SDS-PAGE analysis showed that the intensity of the band from the culture supplemented with $0.1 \mathrm{~g} \mathrm{~L}^{-1}$ hemin was higher than that of $0.5 \mathrm{~g} \mathrm{~L}^{-1}$. According to Zerva et al. [69], the presence of $0.1 \mathrm{~g} \mathrm{~L}^{-1}$ of hemin in the culture medium increases enzyme production more than 20 -fold. With this approach, a soluble and active protein was produced, with a yield of about $290 \mathrm{mg}$ of protein per liter of culture medium. The high production yield obtained in P. pastoris was much higher than that obtained with E. coli production with a few $\mathrm{mg}$ per liter, i.e., Trametes versicolor TvDyP1 and Pleurotus ostreatus DyP isoforms PleosDyP1 and Pleos DyP4 were produced with $1 \mathrm{mg} / 5 \mathrm{~L}$ and 6.3 to $11.7 \mathrm{mg} / 9 \mathrm{~L}$ of $E$. coli cultures, respectively [35,58].

The expected molecular weight for DyP1 was $55 \mathrm{kDa}$, but after purification, the protein ran on SDS-PAGE at about $70 \mathrm{kDa}$, with a $30 \%$ greater apparent molecular weight (Figure $\mathrm{S} 1$ ). This is due to the presence of $\mathrm{N}$ - and O-glycosylations, as already observed for other recombinant proteins produced in P. pastoris [70]. DyP1 was predicted to possess potential N-glycosylation at positions $23,57,67,133,163,215,374$, and 546 , as predicted via the N-GlyDE web server (http:/ / bioapp.iis.sinica.edu.tw/N-GlyDE/, accessed on 19 April 2021). The best transformant was cultured in a larger volume (500 $\mathrm{mL})$, and the recombinant protein was purified by affinity chromatography using an IMAC column. DyP1 was purified to homogeneity (Figure S1) from a culture containing $4682 \mathrm{mg}$ of proteins with a recovery of $63.3 \mathrm{mg}$ of DyP (Table 3). The recovery of the purification was $43.6 \%$, with a purification factor of 32.4.

Table 3. Purification for the recombinant DyP1 produced in Pichia pastoris X33. IMAC: immobilized metal affinity chromatography.

\begin{tabular}{ccccccc}
\hline $\begin{array}{c}\text { Purification } \\
\text { Step }\end{array}$ & $\begin{array}{c}\text { Volume } \\
(\mathbf{m L})\end{array}$ & $\begin{array}{c}\text { Total Activity } \\
\left(\mathbf{U ~ m L}^{-\mathbf{1}}\right)\end{array}$ & $\begin{array}{c}\text { Protein } \\
(\mathbf{m g})\end{array}$ & $\begin{array}{c}\text { Specific Activity } \\
\left(\mathbf{U ~ m g ~}^{-\mathbf{1}}\right)\end{array}$ & Yield (\%) & $\begin{array}{c}\text { Purification } \\
\text { (Fold) }\end{array}$ \\
\hline $\begin{array}{c}\text { Culture } \\
\text { medium }\end{array}$ & 500 & 376 & 4682 & 0.08 & 100 & 1 \\
IMAC & 25 & 164 & 63.3 & 2.59 & 43.6 & 32.4 \\
\hline
\end{tabular}

\subsection{Catalytic Properties}

Six different substrates, i.e., $\mathrm{Mn}^{2+}$, the anthraquinone dye RB19, the low redoxpotential dye ABTS, together with the phenolic and non-phenolic aromatic compounds DMP and VA, were tested to evaluate substrate specificity of recombinant DyP1. The enzyme exhibited activity against ABTS and RB19 only (Table 4), with $K_{\mathrm{m}}$ values of 0.651 and $1.497 \mathrm{mM}$, respectively. No activity was found against DMP, $\mathrm{Mn}^{2+}$, or VA. Catalytic efficiency $\left(K_{\mathrm{cat}} / K_{\mathrm{m}}\right)$ was estimated for the anthraquinone RB19 to $2.23 \mathrm{~s}^{-1} \mathrm{mM}^{-1}$.

Table 4. Kinetic constants of the recombinant DyP1 produced in P. pastoris. The $\mathrm{pH}$ column indicates either the tested $\mathrm{pH}$ range or the determined optimal reaction $\mathrm{pH}$.

\begin{tabular}{ccccc}
\hline \multirow{2}{*}{ Substrate } & \multicolumn{3}{c}{ Parameters } \\
\cline { 2 - 5 } & $\boldsymbol{K}_{\mathbf{m}}(\mathbf{m M})$ & $\boldsymbol{k}_{\text {cat }}\left(\mathbf{s}^{-\mathbf{1}}\right)$ & $\boldsymbol{k}_{\text {cat }} / \boldsymbol{K}_{\mathbf{m}}\left(\mathbf{s}^{-\mathbf{1}} \mathbf{~} \mathbf{m M}^{-\mathbf{1}}\right)$ & $\mathbf{p H}$ \\
\hline ABTS & $0.651+/-0.081$ & 0.322 & 0.49 & 3 \\
RB19 & $1.497+/-0.878$ & 3.34 & 2.23 & 2.6 \\
DMP & 0 & 0 & 0 & $2.6-7$ \\
Mn $^{2+}$ & 0 & 0 & 0 & $2.6-6$ \\
VA & 0 & 0 & 0 & $2.6-7$ \\
\hline
\end{tabular}




\subsection{Enzyme Activity and Stability at Different $p H$ and Temperature}

Recombinant DyP1 was active under acidic $\mathrm{pH}$ conditions with an optimum at $\mathrm{pH} 3$ for ABTS in the $\mathrm{pH}$ range tested (Figure 5A). This value was 2.6 for RB19. At higher $\mathrm{pH}$, the DyP1 activity substantially dropped when the $\mathrm{pH}$ was between 4 and 6, and almost no activity was found at $\mathrm{pH}$ 6.0. The $\mathrm{pH}$ stability of DyP1 was assessed by incubating the enzyme for 4, 24, and $48 \mathrm{~h}$ with ABTS in a $\mathrm{pH}$ range from 2.6 to 6 . The enzyme turned out to be very stable throughout the range of $\mathrm{pH}$ and the activity increased with time, with a marked activation at $\mathrm{pH} 4$ and 5 (Figure 5B). However, the enzyme lost its activity after 48 $\mathrm{h}$ of incubation at $\mathrm{pH} 6$.
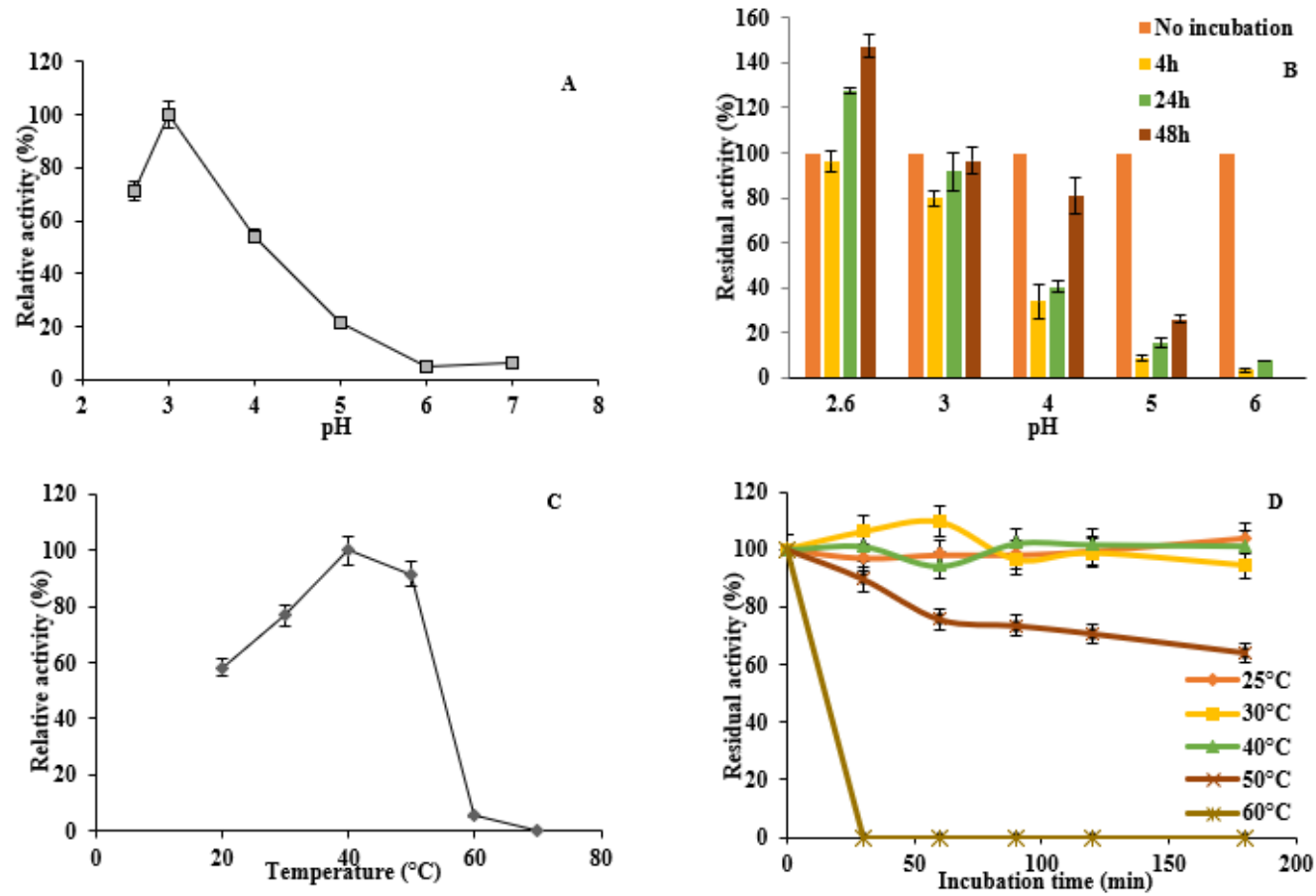

Figure 5. Effect of $\mathrm{pH}$ and temperature on enzyme activity and stability. (A) Optimal pH for the oxidation of ABTS (5 mM); (B) $\mathrm{pH}$ stability in the range $\mathrm{pH}$ 2.6-6 for 4, 24, and $48 \mathrm{~h}$ incubation; (C) optimal temperature for the oxidation of ABTS; and (D) temperature stability in the range $25-70{ }^{\circ} \mathrm{C}$. Enzyme activity was measured in a $0.1 \mathrm{M}$ citrate-phosphate buffer using ABTS $(5 \mathrm{mM})$ as a reducing substrate and $0.25 \mathrm{mM} \mathrm{H}_{2} \mathrm{O}_{2}$ at $30{ }^{\circ} \mathrm{C}$ (and at $\mathrm{pH} 3.0$ in $(\mathbf{C}, \mathbf{D})$. Activity values were calculated as a percentage of maximum activity (set to 100\%) at optimum temperature and $\mathrm{pH}$. Each data point (mean $+/-$ standard deviation) is the result of triplicate experiments.

The optimum temperature for the enzyme activity against ABTS was $40^{\circ} \mathrm{C}$. However, the enzyme was less active in the ranges $20-30$ and $50-55^{\circ} \mathrm{C}(60-80 \%$, respectively, compared to its activity at $40^{\circ} \mathrm{C}$ ), and nearly lost its activity at $60^{\circ} \mathrm{C}$ (Figure 5C). The thermal stability of DyP1 was examined by testing activity towards ABTS after heat treatment of the enzyme at different temperatures and for various incubation times, ranging from 30 to $180 \mathrm{~min}$. The enzyme was stable at temperatures ranging from 30 to $50^{\circ} \mathrm{C}$, retaining about $60 \%$ of initial activity after $180 \mathrm{~min}$ of incubation at $50{ }^{\circ} \mathrm{C}$. However, at $60^{\circ} \mathrm{C}$ and above, no activity remained after $30 \mathrm{~min}$ of incubation (Figure 5D).

\subsection{Decolorization of Industrial Dyes}

Because of its potential for dye decolorization, DyP1 activity was tested on five more industrially relevant dyes, belonging to five different chemical classes: acidic, basic, reactive, vat, and disperse dyes. As shown in Table 5, DyP1 was highly active on Reactive Black 5 (RB5) dye (32.3\% of decolorization) and to a lesser extent on Acid Black (AB) and Disperse Blue 79 (DB). By contrast, TvDyP1 from T. versicolor (GenBank accession numbers 19415892) was active only against $A B$, though with $75 \%$ of decolorization. 
Table 5. Decolorization of industrial dyes by the recombinant DyP ${ }^{\mathrm{a}}$.

\begin{tabular}{|c|c|c|}
\hline Dye & DyP1 & TvDyP1 \\
\hline $\mathrm{AB}$ & $18.8+/-0.008$ & $75.0+/-0.007$ \\
\hline $\mathrm{BB}$ & - & - \\
\hline RB5 & $32.3+/-0.009$ & - \\
\hline DB79 & $5.2+/-0.005$ & - \\
\hline VG & - & - \\
\hline
\end{tabular}

\subsection{Effect of Hydrogen Peroxide on DyP1 Activity}

Although hydrogen peroxide is the electron acceptor of peroxidases, these enzymes are known to lose activity in the presence of $\mathrm{H}_{2} \mathrm{O}_{2}$, through a mechanism known as suicide inactivation [71]. The optimum concentration of $\mathrm{H}_{2} \mathrm{O}_{2}$ was determined by incubating the reaction mixture with different concentrations of $\mathrm{H}_{2} \mathrm{O}_{2}$, ranging from 0.1 to $5 \mathrm{mM}$, and the highest DyP1 activity was recorded for $0.25 \mathrm{mM} \mathrm{H}_{2} \mathrm{O}_{2}$ (Figure 6A). Above this concentration, DyP1 residual activity decreased gradually, up to $30 \%$ at $5.0 \mathrm{mM} \mathrm{H}_{2} \mathrm{O}_{2}$.
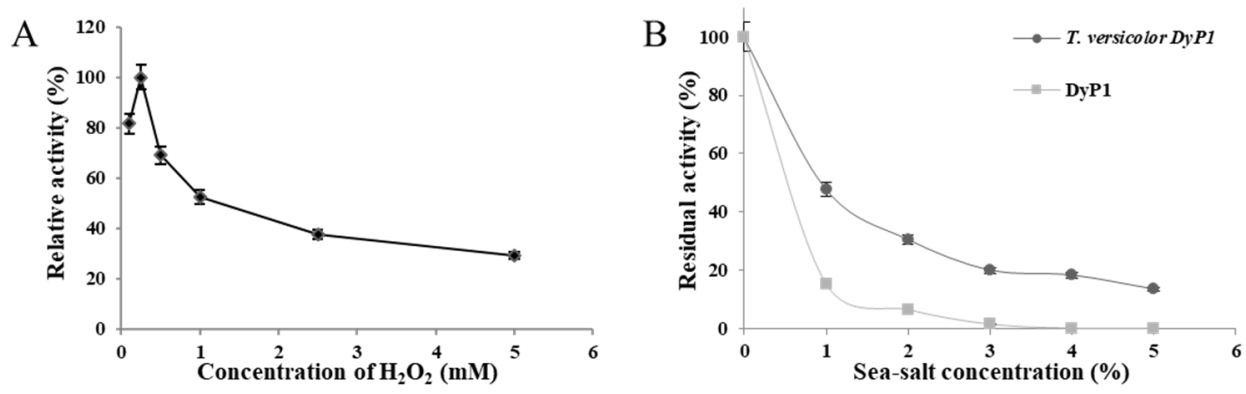

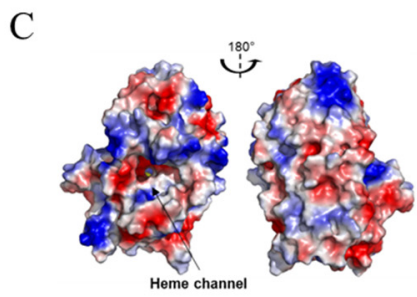

DyP1

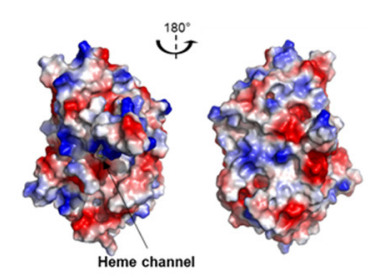

T. versicolor DyP1

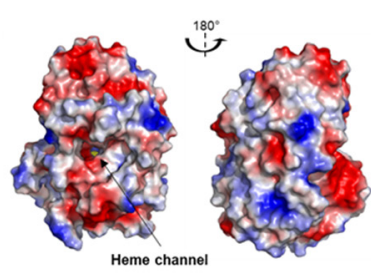

A. auricularia-judae DyP

Figure 6. Effect of hydrogen peroxide and sea salt on DyP1 activity and surface charges of three different fungal DyPs. (A) The optimal concentration of hydrogen peroxide in standard conditions, using ABTS (5 mM) as a substrate. (B) Effect of sea salt addition on recombinant DyP1 and T. versicolor DyP (TvDyP1) as a control. Relative enzymatic activity recorded as in (A). Each data point (mean $+/$ - standard deviation) is the result of triplicate experiments. (C) Surface charge plots (negative and positive charges in red and blue, respectively) from homology models of DyP1 and TvDyP1 (GenBank accession numbers 19415892) and from the experimental three-dimensional structure of AauDyP from A. auricula-judae (PDB: 4W7J). The heme cofactor, deeply buried within the active site, is hardly visible (yellow spheres). Surface potentials were calculated using the vacuum electrostatics function of the PyMOL molecular graphics system (Schrödinger, New York, NY, USA).

\subsection{Influence of Sea Salt on DyP1 Activity and Surface Charge of the Recombinant DyP1}

Recombinant DyP1, identified in mangrove sediments, was compared with TvDyP1, active in terrestrial environments, to gain insights into DyP1 adaptation to saline conditions, as found in marine environments. As we can see in the results presented in Figure 6, the activity of the purified DyP1 was affected by sea salt addition (Figure 6B). From 1\% of sea salt addition, the enzyme retained less than $20 \%$ of its initial activity. At $3 \%$ of sea salt, the 
recombinant DyP1 activity was severely affected by sea salt, even more than its terrestrial counterpart, TvDyP1.

Three-dimensional models of recombinant DyP1 and TvDyP1 were generated, and the overall surface charges were compared with AauDyp (Figure 5C). The three enzymes showed a well-balanced ratio of negative to positive surface charges. In line with these results, analysis of the enzyme primary structure showed that the ratio of negatively charged $(\mathrm{D}+\mathrm{E})$ over positively charged $(\mathrm{R}+\mathrm{K})$ amino acids was about $1.19,1.16$, and 1.24 for the recombinant DyP1, TvDyP1, and AauDyP, respectively. By contrast, a lytic-polysaccharide monooxygenase cloned from the mangrove fungus, Pestalotiopsis sp NCi6 (PsLPMOA), and a laccase obtained from the marine-derived Pestalotiopsis sp KF079 possessed higher $(\mathrm{D}+\mathrm{E}) /(\mathrm{R}+\mathrm{K})$ ratios of 4.8 and 3.95, respectively.

\section{Discussion}

The mangrove ecosystem accounts for a large production of lignocellulosic biomass and greatly contributes to carbon sequestration on the planetary scale [72]. Fungi are colonizers of mangrove forests, and the representative species form a large and diversified ecological group, playing a central role in the degradation of lignocellulosic sedimentary organic matter [73]. Lignocellulose biomass degradation is based on the secretion of a broad variety of enzymes that have different, complementary catalytic activities, including cellulases, hemicellulases, and lignin-modifying enzymes [74]. In this study, we focused on DyPs as model lignin-modifying enzymes, because enzymes from this family are present in Ascomycota and Basidiomycota, and both Phyla were identified in New Caledonian mangrove sediments [3]. These enzymes have been suggested to contribute to the degradation of phenolic residues and the modification of lignin-derived soil organic matter [61].

The diversity of expressed genes encoding fungal DyPs was investigated in both surface and buried mangrove sediments underneath $A$. marina and $R$. stylosa trees, and during the wet (March) and the dry (November) seasons. Compared to soils from terrestrial forests, which can harbor a high diversity of expressed lignolytic genes (e.g., from 82 to 253 DyP OFUs [75]), mangrove sediments showed much narrower diversity, with only 25 DyP OFUs retrieved, possibly the result of physical-chemical gradients associated with mangroves sediments that are inimical to fungal ligninolytic enzyme activities (e.g., low oxygen and nitrogen contents [76]). DyP diversity was also strongly affected by the season, as already observed for the fungal community composition [35]. A systematic decrease in DyP diversity was observed in surface layers during the dry season (November). In previous studies, wet seasons appeared favorable to microbial colonization in mangrove ecosystems, particularly for fungi [73], as salinity and temperature decrease and increase, respectively $[77,78]$. Moreover, the water availability is an important factor regulating fungal activity in mangrove sediments [79]. However, in our study, DyP diversity was lower in the wet season, except for surface layer sediments collected during the wet season beneath $R$. stylosa. The impact of tree species on DyP composition is consistent with previous work conducted in forest ecosystems, showing that tree species and more particularly species-generated soil $\mathrm{C} / \mathrm{N}$ ratio are the most important factors driving functional gene distribution [75]. However, in New Caledonian mangrove habitats, salinity is also an important factor. It shapes tree distribution, impacting directly or indirectly on the taxonomic and functional diversity of sediment fungal communities [80]. Random high-throughput (Hiseq) sequencing of environmental cDNA after gene capture by hybridization enabled us to identify the full-length sequence of the most abundant fungal OFU in mangrove sediments, DyP1, whose sequence was successfully cloned and expressed in P. pastoris.

The origin of DyP1 was inferred from phylogenetic analysis, and a biochemical characterization was conducted to determine its physical-chemical properties, kinetic parameters, and potential for biotechnological applications, such as dye decolorization. Phylogenetic analysis revealed a sequence similarity from (47\% to 59\%) of the recombinant DyP1 with those of DyPs from four species of the orders Auriculariales and Sebacinales (Basidiomycota, Agaricomycotina), including E. glandulosa, A. delicata, P. indica, and S. vermifera. This result 
is in agreement with our previous finding that Basidiomycota was mainly represented by Agaricomyceta [3]. Although Ascomycota largely dominated the analyzed mangrove sediments (73.8-94.5\% of total ITS sequences), Basidiomycota represented $5.3-26.2 \%$ of total ITS sequences [3]. Interestingly, Agaricomycotina represented 5.3-18.3\% of total ITS sequences, i.e., most of the Basidiomycete sequences, and operational taxonomic units (OTUs) affiliated to the genus Exidia were detected in mangrove sediments.

The structural model of DyP1 highlighted the presence of the heme cofactor and a ferredoxin-like fold forming the CDE superfamily. Asp 213 and Arg 371 were identified showing the conserved motif GXXDG residues and their contribution in the heterolytic cleavage of $\mathrm{H}_{2} \mathrm{O}_{2}$ to activate the enzyme. This result was similar to AauDyP where Aspartate and Arginine were located in positions 168 and 332, respectively [61], and to P. sapidus DyP with Asp174 and Arg338 [66]. Additionally, the fifth ligand of the heme iron of DyP1, histidine 351, was detected with an aspartate at position 433 forming a hydrogen bond similar to the recombinant PsaDyP (His 317 and Asp 401) and AauDyP (His304 and Asp395). However, in some cases, the aspartate residue was substituted by a glutamic acid $[61,66]$. The homology modeling admits the catalytic activity of the Trp 416 of DyP1, which was tendentially like A. auricularia-judae (Trp 377) and T. versicolor DyP (Trp 411) [30,61]. To oxidize a large number of substrates, DyP1 shows an aromatic surface with tryptophane and tyrosine residues. This result was in line with PsaDyP, where Tyr343 and Trp383 were conserved solvent-exposed residues, and with Pleurotus eryngii VP, where Trp164 plays a key role in the direct electron transfer $[66,68]$.

Among the five substrates tested, including $\mathrm{Mn}^{2+}$, recombinant DyP1 showed activity on ABTS and RB19 only, with higher affinity for the former $\left(K_{m}, 651.39 \mu \mathrm{M}\right)$ than for the latter $\left(K_{\mathrm{m}}, 1497.07 \mu \mathrm{M}\right)$. Affinities for ABTS and RB19 were higher for TvDyP1 $\left(K_{m}\right.$, 292 and $37.8 \mu \mathrm{M}$, respectively) and AauDyP $\left(K_{\mathrm{m}}, 283\right.$ and $6.5 \mu \mathrm{M}$ respectively). For $P$. ostreatus DyPs, Pleos yP1/ PleosDyP4 $K_{\mathrm{m}}$ values were 780 and $787 \mu \mathrm{M}$ for ABTS, and 45 and $82 \mu \mathrm{M}$ for RB19, respectively [58]. I. lacteus DyP also showed higher affinity to ABTS ( $K_{\mathrm{m}}$ $28 \mu \mathrm{M})$ than to RB19 $\left(K_{\mathrm{m}} 13 \mu \mathrm{M}\right)$ [65]. Catalytic efficiency of DyP1 was 4-5 times higher for $\operatorname{RB} 19\left(k_{\text {cat }} / K_{\mathrm{m}}, 2.23 \mathrm{~s}^{-1} \mathrm{mM}^{-1}\right)$ than for ABTS $\left(k_{\text {cat }} / K_{\mathrm{m}}, 0.49 \mathrm{~s}^{-1} \mathrm{mM}^{-1}\right)$, whereas catalytic efficiency on ABTS was 3, 2, and 0.7 times higher than catalytic efficiency on RB19, for TvDyP1, PleosDyP1/ PleosDyP4, and I. lacteus DyP, respectively [30,58,65]. In conclusion, although the catalytic efficiencies of recombinant DyP1 were lower than for the above characterized DyPs, they were still in the range of what was found for DyPs isolated from terrestrial environments.

The structural homology model obtained for DyP1 presents both the heme cofactor and the ferredoxin-like fold characteristic of the CDE superfamily [23]. A detailed analysis revealed all the elements characterizing a catalytically active DyP. Thus, Asp213 and Arg371 located over the heme plane (at the so-called distal side) are expected to contribute to the enzyme activation by $\mathrm{H}_{2} \mathrm{O}_{2}$ as previously demonstrated for distal aspartate and arginine in Aau DyP [20]. Similarly, the key residues located below the heme plane (the so-called proximal side) are conserved when compared with other DyPs. In this region, His351 therefore acts as the fifth ligand of the heme iron, and the interaction between this histidine and the neighboring Asp433 may be responsible for the redox potential of the enzyme, as suggested by Linde et al. [61]. Concerning the putative catalytic sites for substrate oxidation, the heme access channel and the surface Trp416, which occupies a position equivalent to that of the catalytic Trp377 in AauDyP, are the main candidates. The former has been suggested to be the low-efficiency site for ABTS and RB9 oxidation, while the solvent-exposed Trp377 has been demonstrated to be the high-efficiency site for these two substrates in the A. auricula-judae enzyme [20]. Unlike this enzyme, DyP1 presents a set of kinetic constants for these two substrates, indicating that only one of these two sites is active, although other alternative sites cannot be ruled out. Among them, we found other solvent-exposed tryptophan and tyrosine residues that could also act as catalytic residues instead of Trp377. They could be activated by long-range electron transfer pathways in a similar way as described for Trp377 in AauDyP [61] and for different Trp and Tyr residues in 
ligninolytic peroxidases [81-83]. Directed mutagenesis studies of these residues and at the heme access channel are necessary to definitively identify the catalytic site of this enzyme.

Enzymatic activity on ABTS of purified recombinant DyP1 was optimal at $\mathrm{pH} 3$, similar to what was reported for DyPs from I. lacteus [65], T. versicolor [30], P. sapidus [66], A. auriculajudae [29], and Pleurotus ostreatus [58]. Recombinant DyP1 is stable at acid pH (2.6-5.0), with activity increase for longer incubations at $\mathrm{pH} 4.0$ and 5.0. At pH 6.0, enzyme activation was observed for $24 \mathrm{~h}$, whereas after a longer incubation time, activity was completely abolished. For TvDyP, P PleosDyP1/PleosDyP4, and I. lacteus DyP, stability was similar in the same $\mathrm{pH}$ range, but no activation effect at $\mathrm{pH} 4.0$ and 5.0 was observed $[30,58,65]$. The effect of temperature on DyP1 activity and stability was measured at different temperature points ranging from 30 to $70{ }^{\circ} \mathrm{C}$. Recombinant DyP1 showed optimal activity at $40{ }^{\circ} \mathrm{C}$ and retained $60-80 \%$ residual activity after $180 \mathrm{~min}$ incubation at temperatures in the range of $30-50{ }^{\circ} \mathrm{C}$. For corresponding temperatures, TvDyP1 retained only $5-35 \%$ activity, and PleosDyP1 was inactive, although Pleos-DyP4 maintained 100\% activity even in the range of $60-70{ }^{\circ} \mathrm{C}[30,58]$. Finally, P. sapidus DyP (PsaDyP) was active in the temperature range of $15-30{ }^{\circ} \mathrm{C}$ but had already lost $50 \%$ activity after $5 \mathrm{~min}$ incubation at $50{ }^{\circ} \mathrm{C}$ [66]. Although $\mathrm{H}_{2} \mathrm{O}_{2}$ is a peroxidase co-substrate, it is also known to inactivate enzyme activity above a critical, enzyme-specific concentration. Optimal activity for recombinant DyP1 was recorded at $0.25 \mathrm{mM} \mathrm{H}_{2} \mathrm{O}_{2}$. This value lies within the range of values determined for other DyPs: $0.125 \mathrm{mM}$ for PsaDyP, $0.5 \mathrm{mM}$ for TvDyP1, and 0.4 to $0.8 \mathrm{mM}$ for I. lacteus DyP $[30,65,66]$.

To assess the potential of recombinant DyP1 as a biocatalyst for applications in white biotechnology, we tested its capacity to decolorize the industrial dyes already tested for TvDyP1 [30]. DyP1 was active on three dyes (AB, RB5, and DB79), corresponding to different chemical classes (acidic, reagent, and disperse dyes), whereas TvDyP1 was only active on $\mathrm{AB}$, though with a higher efficiency (75\% decolorization). DyP1 instead showed higher substrate versatility, suggesting an original technological potential for largespectrum dye bleaching, and showed the best efficiency on RB5 (32\% decolorization). In several studies, RB5 is reported as a well-known recalcitrant azo dye, with a rigid aromatic molecule that is difficult to degrade. This compound is dangerous, carcinogenic, and toxic to humans and the environment [84]. In previous studies, RB5 was decolorized by various fungal strains, such as P. eryngii F032 (94\% decolorization) [85], Geotrichum candidum Dec 1 (94\%) [86], Cerrena sp. WICC F39 (86\%) [87], Funalia trogii (95\%) [88], and Trametes gibossa WRF3 (82\%) [84]. These results open a field of application for the recombinant DyP1 that needs to be further developed, for instance by immobilizing the enzyme to improve its efficiency [89].

To complete enzyme characterization, and as the recombinant DyP1 was obtained from a marine environment (mangrove of New Caledonia), we tested the behavior of DyP1 in saline conditions. Despite its marine origins, recombinant DyP1 was similarly affected by sea salt, compared with terrestrial-derived TvDyP1. By contrast, marine Phlebia sp. MnP showed four times higher activity when the culture medium was supplemented with $3 \%$ of sea salt [15]. Furthermore, two laccases recently cloned from the marinederived fungus Pestalotiopsis sp. KF079, isolated from the Baltic sea mudflats, were strongly activated by up to $360 \%$ of their initial activity in the presence of $5 \%(w / v)$ sea salt [33]. We also demonstrated that lytic polysaccharide monooxygenases from the mangrove fungus Pestalotiopsis sp. NCi6 (PsLPMOA) remained active even at 6.0\% (w/v) sea salt [90].

Salt-adapted enzymes originating from marine environments are generally characterized by highly negative surface charges thought to contribute to protein stability and activity in extreme osmolytic conditions [91-93]. In our results, the recombinant DyP1 had a low $(\mathrm{D}+\mathrm{E}) /(\mathrm{R}+\mathrm{K})$ ratio of 1.19 , which is the same as for the terrestrial-derived TvDyP1 (1.16) and AauDyP (1.24). In line with these results, this ratio for the laccases $M t$ Lac from the terrestrial Myceliophthora thermophila was 1.55, and for PsLac1 from the marine-derived Pestalotiopsis sp. and SlLac2 from S. lucomagnoense 1.55 and 1.2, respectively, despite their marine origin [14,33]. By contrast, the laccase PsLac2 and PsLPMOA enzymes 
isolated from Pestalotiopsis $s p$. had a four-times higher recurrence of negatively (D + E) than positively charged $(\mathrm{R}+\mathrm{K})$ amino acids $[33,90]$. This observation was supported by comparing the homology-guided three-dimensional models generated for two DyPs revealing a well-balanced surface charge distribution, while for the PsLac2 and PsLPMOA enzymes highly negative residues were exposed at the surface $[33,92]$. We can thus conclude that the surface charge distribution of mangrove-derived DyP1 is reminiscent of those of terrestrial DyPs. Mangrove habitats are detritus-based ecosystems, colonized by a large community of terrestrial saprotrophic fungi [73]. Future experiments will be needed to compare the structural organization of the mangrove soil at the taxonomic and functional levels. To achieve this goal, it will be pivotal to clone and characterize other DyPs identified in the mangrove soil samples and to study DyP biodiversity as a function of depth, vegetation, and season. Similar studies should be also conducted on other lignocellulose-degrading enzymes to validate this approach and corroborate these results.

\section{Conclusions}

Mangrove habitats are rich ecosystems, extremely diverse because of the combination of highly variable environmental gradients related to salinity, temperature, humidity, depth, tree species, and many more variables. This results in a rich biodiversity and diverse microbial distribution, constituting as such a very original model environment to characterize. In the present work, gene capture by hybridization combined with highthroughput sequencing allowed the detection of fungal functional cDNAs encoding DyPs, whose expressions were lower than the genes identified in conventional forest soils, and the discovery of novel biocatalysts. We also expressed and characterized the most frequently encountered and abundant DyP from the explored mangrove. We conclude that the newly discovered DyP1 is expressed from a fungal species within the genus Exidia and that the enzyme has biochemical properties close to their terrestrial isoforms, although likely endowed with greater substrate versatility.

Supplementary Materials: The following are available online at https://www.mdpi.com/article/ 10.3390/jof7050321/s1. Table S1: List of tagged primers used to amplify expressed genes encoding fungal Dye-decolorizing Peroxidases (DyPs); Table S2: Normalized dataset where the 781,344 fungal DyP sequences are distributed among the 25 different Operational Functional Units (OFUs) within the sediment samples; Table S3: Mean number of fungal DyP OFUs (Operational Function Units) detected and diversity indices calculated for oxic and anoxic sediment fractions collected during the wet (March) and dry (November) seasons within two mangrove pristine areas (Avicennia marina and Rhizophora stylosa); Figure S1: title: SDS-PAGE of the two-step purification for the recombinant DyP1 produced in Pichia pastoris. Lanes: 1, culture medium fraction; 2, purified DyP1 obtained after IMAC chromatography and $\mathrm{M}$, protein molecular mass markers.

Author Contributions: G.S.-G., L.V., A.T.-D. and M.H. (Mireille Haon) provided experiment support; M.D., M.A., R.M., S.C.-M., P.P. and D.A. provided technical support and contributed to the discussion; A.B.A., D.L., F.J.R.-D., C.M., M.H. (Mylène Hugoni), P.L., T.M. and E.R. designed the experiments; and A.B.A., D.L., E.B., C.B.F., G.S., F.J.R.-D., C.M., M.H. (Mylène Hugoni), P.L., T.M. and E.R. wrote the manuscript. All authors have read and agreed to the published version of the manuscript.

Funding: This research was funded by the ECosphère Continentale et Côtière MicroBien program (EC2CO, 2017-2019) and by the Agence Nationale de la Recherche (project PeroxiDiv ANR-RF2015-01). D.L. and F.J.R-D. were supported by H2020 BBI-JU (https:/ / www.bbi-europe.eu) EnzOx2 (H2020-BBI-PPP-2015-2-720297; https:/ / www.enzox2.eu) project and GENOBIOREF (BIO2017-86559R) project of the Spanish Ministry of Science \& Innovation (co-financed by FEDER funds).

Institutional Review Board Statement: Not applicable.

Informed Consent Statement: Not applicable.

Acknowledgments: The authors are grateful to MN Rosso, INRAE Aix-Marseille University, and Igor V Grigoriev, Joint Genome Institute, for providing access to genome sequence data for Trametes betulina BRFM 1801, Trametopsis cervina BRFM1824, Trametes cingulata BRFM1805, Trametes gibbosa 
BRFM 1770, Trametes ljubarskyi BRFM 1659, Trametes maxima BRFM 1813, Trametes meyenii BRFM 1810, and Trametes polyzona BRFM 1798.

Conflicts of Interest: The authors declare they have no conflict of interest. The funders had no role in the design of the study; or in the collecting, analysis, or interpretation of data; in the writing of the manuscript; or in the decision to publish the results.

\section{References}

1. Thatoi, H.; Behera, B.C.; Mishra, R.R. Ecological role and biotechnological potential of mangrove fungi: A review. Mycology 2013, 4, 54-71. [CrossRef]

2. Kathiresan, K.; Bingham, B.L. Biology of mangroves and mangrove ecosystems. Adv. Mar. Biol. 2001, 40, 84-254.

3. Luis, P.; Saint-Genis, G.; Vallon, L.; Bourgeois, C.; Bruto, M.; Marchand, C.; Record, E.; Hugoni, M. Contrasted ecological niches shape fungal and prokaryotic community structure in mangroves sediments. Environ. Microbiol. 2019, 21, 1407-1424. [CrossRef] [PubMed]

4. Latha, R.; Mitra, S. Mangrove fungi in India. Curr. Sci. 2004, 86, 1586.

5. Kida, M.; Fujitake, N. Organic Carbon Stabilization Mechanisms in Mangrove Soils: A Review. Forests 2020, 11, 981. [CrossRef]

6. Chen, G.; Azkab, M.H.; Chmura, G.L.; Chen, S.; Sastrosuwondo, P.; Ma, Z.; IWayan, E.D.; Xijie, Y.; Chen, B. Mangroves as a major source of soil carbon storage in adjacent seagrass meadows. Sci. Rep. 2017, 7, 42406. [CrossRef] [PubMed]

7. Hyde, K.D.; Lee, S.Y. Ecology of mangrove fungi and their role in nutrient cycling-What gaps occur in our knowledge. Hydrobiologia 1995, 295, 107-118. [CrossRef]

8. López-Mondéjar, R.; Zühlke, D.; Becher, D.; Riedel, K.; Baldrian, P. Cellulose and hemicellulose decomposition by forest soil bacteria proceeds by the action of structurally variable enzymatic systems. Sci. Rep. 2016, 6, 25279. [CrossRef]

9. Datta, R.; Kelkar, A.; Baraniya, D.; Molaei, A.; Moulick, A.; Meena, R.S.; Formanek, P. Enzymatic degradation of lignin in soil: A review. Sustainability 2017, 9, 1163. [CrossRef]

10. Levasseur, A.; Drula, E.; Lombard, V.; Coutinho, P.M.; Henrissat, B. Expansion of the enzymatic repertoire of the CAZy database to integrate auxiliary redox enzymes. Biotechnol. Biofuels 2013, 6, 1-14. [CrossRef]

11. Arfi, Y.; Chevret, D.; Henrissat, B.; Berrin, J.G.; Levasseur, A.; Record, E. Characterization of salt-adapted secreted lignocellulolytic enzymes from the mangrove fungus Pestalotiopsis sp. Nat. Commun. 2013, 4, 1-9. [CrossRef]

12. Ben Ali, W.; Navarro, D.; Kumar, A.; Drula, E.; Turbé-Doan, A.; Correia, L.O.; Baumberger, S.; Bertrand, E.; Faulds, C.B.; Henrissat, B.; et al. Characterization of the CAZy Repertoire from the Marine-Derived Fungus Stemphylium lucomagnoense in Relation to Saline Conditions. Mar. Drugs 2020, 18, 461. [CrossRef]

13. Bucher, V.V.C.; Pointing, S.B.; Hyde, K.D.; Reddy, C.A. Production of Wood Decay Enzymes, Loss of Mass, and Lignin Solubilization in Wood by Diverse Tropical Freshwater Fungi. Microb. Ecol. 2004, 48, 331-337. [CrossRef] [PubMed]

14. Ben Ali, W.; Ayed, A.B.; Turbé-Doan, A.; Bertrand, E.; Mathieu, Y.; Faulds, C.B.; Lomascolo, A.; Sciara, G.; Record, E.; Mechichi, T. Enzyme Properties of a Laccase Obtained from the Transcriptome of the Marine-Derived Fungus Stemphylium lucomagnoense. Int. J. Mol. Sci. 2020, 21, 8402. [CrossRef]

15. Kamei, I.; Daikoku, C.; Tsutsumi, Y.; Kondo, R. Saline-dependent regulation of manganese peroxidase genes in the hypersalinetolerant white rot fungus Phlebia sp. strain MG-60. Appl. Environ. Microb. 2008, 74, 2709-2716. [CrossRef]

16. Zámocký, M.; Hofbauer, S.; Schaffner, I.; Gasselhuber, B.; Nicolussi, A.; Soudi, M.; Pirker, K.F.; Furtmüller, P.G.; Obinger, C. Independent evolution of four heme peroxidase superfamilies. Arch. Biochem. Biophys. 2015, 574, 108-119. [CrossRef]

17. Acharya, G.; Kaur, G.; Subramanian, S. Evolutionary relationships between heme-binding ferredoxin $\alpha+\beta$ barrels. BMC Bioinform. 2016, 17, 1-11. [CrossRef] [PubMed]

18. Celis, A.I.; DuBois, J.L. Substrate, product, and cofactor: The extraordinarily flexible relationship between the CDE superfamily and heme. Arch. Biochem. Biophys. 2015, 574, 3-17. [CrossRef] [PubMed]

19. Yoshida, T.; Sugano, Y. A structural and functional perspective of DyP-type peroxidase family. Arch. Biochem. Biophys. 2015, 574, 49-55. [CrossRef]

20. Linde, D.; Pogni, R.; Cañellas, M.; Lucas, F.; Guallar, V.; Baratto, M.C.; Sinicropi, A.; Sáez-Jiménez, V.; Coscolín, C.; Romero, A.; et al. Catalytic surface radical in dye-decolorizing peroxidase: A computational, spectroscopic and directed mutagenesis study. Biochem. J. 2015, 466, 253-262. [CrossRef]

21. Sciara, G.; Kendrew, S.G.; Miele, A.E.; Marsh, N.G.; Federici, L.; Malatesta, F.; Giuliana, S.; Carmelinda, S.; Vallone, B. The structure of ActVA-Orf6, a novel type of monooxygenase involved in actinorhodin biosynthesis. EMBO J. 2003, 22, 205-215. [CrossRef]

22. Thompson, T.B.; Katayama, K.; Watanabe, K.; Hutchinson, C.R.; Rayment, I. Structural and Functional Analysis of Tetracenomycin F2 Cyclase fromStreptomyces glaucescens. J. Biol. Chem. 2004, 279, 37956-37963. [CrossRef]

23. Goblirsch, B.; Kurker, R.C.; Streit, B.R.; Wilmot, C.M.; DuBois, J.L. Chlorite dismutases, DyPs, and EfeB: 3 microbial heme enzyme families comprise the CDE structural superfamily. J. Mol. Biol. 2011, 408, 379-398. [CrossRef] [PubMed]

24. Sugano, Y. DyP-type peroxidases comprise a novel heme peroxidase family. Cell Mol. Life Sci. 2009, 66, 1387-1403. [CrossRef] [PubMed]

25. Sugawara, K.; Nishihashi, Y.; Narioka, T.; Yoshida, T.; Morita, M.; Sugano, Y. Characterization of a novel DyP-type peroxidase from Streptomyces avermitilis. J. Biosci. Bioeng. 2017, 123, 425-430. [CrossRef] 
26. Gomi, N.; Yoshida, S.; Matsumoto, K.; Okudomi, M.; Konno, H.; Hisabori, T.; Sugano, Y. Degradation of the synthetic dye amaranth by the fungus Bjerkandera adusta Dec 1: Inference of the degradation pathway from an analysis of decolorized products. Biodegradation 2011, 22, 1239-1245. [CrossRef]

27. Faraco, V.; Piscitelli, A.; Sannia, G.; Giardina, P. Identification of a new member of the dye-decolorizing peroxidase family from Pleurotus ostreatus. World J. Microbiol. Biotechnol. 2007, 23, 889-893. [CrossRef]

28. Liers, C.; Bobeth, C.; Pecyna, M.; Ullrich, R.; Hofrichter, M. DyP-like peroxidases of the jelly fungus Auricularia auricula-judae oxidize nonphenolic lignin model compounds and high-redox potential dyes. Appl. Microbiol. Biotechnol. 2010, 85, 1869-1879. [CrossRef]

29. Linde, D.; Coscolin, C.; Liers, C.; Hofrichter, M.; Martínez, A.T.; Ruiz-Dueñas, F.J. Heterologous expression and physicochemical characterization of a fungal dye-decolorizing peroxidase from Auricularia auricula-judae. Protein Expr. Purif. 2014, 103 , 28-37. [CrossRef]

30. Amara, S.; Perrot, T.; Navarro, D.; Deroy, A.; Benkhelfallah, A.; Chalak, A.; Daou, M.; Chevret, D.; Faulds, C.B.; Berrin, J.G.; et al. Enzyme activities of two recombinant heme-containing peroxidases, TvDyP and TvVP2, identified from the secretome of Trametes versicolor. Appl. Environ. Microbiol. 2018, 84, e02826-17. [CrossRef]

31. Hofrichter, M.; Ullrich, R.; Pecyna, M.J.; Liers, C.; Lundell, T. New and classic families of secreted fungal heme peroxidases. Appl. Microbiol. Biotechnol. 2010, 87, 871-897. [CrossRef]

32. Brenelli, L.B.; Persinoti, G.F.; Cairo, J.P.L.F.; Liberato, M.V.; Gonçalves, T.A.; Otero, I.V.R.; Mainardi, P.H.; Felby, C.; Sette, L.D.; Squina, F.M. Novel redox-active enzymes for ligninolytic applications revealed from multiomics analyses of Peniophora sp. CBMAI 1063, a laccase hyper-producer strain. Sci. Rep. 2019, 9, 1-15. [CrossRef]

33. Wikee, S.; Hatton, J.; Turbé-Doan, A.; Mathieu, Y.; Daou, M.; Lomascolo, A.; Kumar, A.; Lymyong, A.; Sciara, G.; Faulds, C.B.; et al. Characterization and Dye Decolorization Potential of Two Laccases from the Marine-Derived Fungus Pestalotiopsis sp. Int. J. Mol. Sci. 2019, 20, 1864. [CrossRef]

34. Chen, H.Y.; Xue, D.S.; Feng, X.Y.; Yao, S.J. Screening and production of ligninolytic enzyme by a marine-derived fungal Pestalotiopsis sp. J63. Appl. Biochem. Biotechnol. 2011, 165, 1754-1769. [CrossRef] [PubMed]

35. Yang, J.; Wang, Z.; Lin, Y.; Ng, T.B.; Ye, X.; Lin, J. Immobilized Cerrena sp. laccase: Preparation, thermal inactivation, and operational stability in malachite green decolorization. Sci. Rep. 2017, 7, 1-9. [CrossRef] [PubMed]

36. Rehner, S.A.; Buckley, E. A Beauveria phylogeny inferred from nuclear ITS and EF1-a sequences: Evidence for cryptic diversification and links to Cordyceps teleomorphs. Mycologia 2005, 97, 84-98. [CrossRef] [PubMed]

37. Sambrook, J.; Russell, D. The Condensed Protocols from Molecular Cloning: A Laboratory Manual, 1st ed.; Cold Spring Harbor Laboratory Press: Cold Spring Harbor, NY, USA, 2006.

38. Grigoriev, I.V.; Nikitin, R.; Haridas, S.; Kuo, A.; Ohm, R.; Otillar, R.; Riley, R.; Salamov, A.; Zhao, X.; Korzeniewski, F.; et al. MycoCosm portal: Gearing up for 1000 fungal genomes. Nucleic Acids Res. 2014, 42, D699-D704. [CrossRef]

39. Savelli, B.; Li, Q.; Webber, M.; Jemmat, A.; Robitaille, A.; Zamocky, M.; Mathé, C.; Dunand, C. RedoxiBase: A database for ROS homeostasis regulated proteins. Redox Biol. 2019, 26, 101247. [CrossRef] [PubMed]

40. Parisot, N.; Denonfoux, J.; Dugat-Bony, E.; Peyret, P.; Peyretaillade, E. KASpOD-a web service for highly specific and explorative oligonucleotide design. Bioinformatics 2012, 28, 3161-3162. [CrossRef] [PubMed]

41. Bragalini, C.; Ribière, C.; Parisot, N.; Vallon, L.; Prudent, E.; Peyretaillade, E.; Girlanda, M.; Peyret, P.; Marmeisse, R.; Luis, P. Solution hybrid selection capture for the recovery of functional full-length eukaryotic cDNAs from complex environmental samples. DNA Res. 2014, 21, 685-694. [CrossRef] [PubMed]

42. Kellner, H.; Luis, P.; Pecyna, M.J.; Barbi, F.; Kapturska, D.; Krüger, D.; Zak, D.R.; Marmeisse, R.; Vandenbol, M.; Hofrichter, M. Widespread occurrence of expressed fungal secretory peroxidases in forest soils. PLoS ONE 2014, 9, e95557. [CrossRef] [PubMed]

43. Zhang, J.; Kobert, K.; Flouri, T.; Stamatakis, A. PEAR: A fast and accurate Illumina Paired-End reAd mergeR. Bioinformatics 2014 30, 614-620. [CrossRef] [PubMed]

44. Mahé, F.; Rognes, T.; Quince, C.; De Vargas, C. Swarm: Robust and fast clustering method for amplicon-based studies. Peer J. 2014, 2, e593. [CrossRef]

45. Rognes, T.; Flouri, T.; Nichols, B.; Quince, C.; Mahé, F. VSEARCH: A versatile open-source tool for metagenomics. Peer J. 2016, 4 , e2584. [CrossRef] [PubMed]

46. Escudie, F.; Auer, L.; Bernard, M.; Mariadassou, M.; Hernadez-Raquet, M.; Pascal, G. FROGS: Find, rapidly, OTUs with Galaxy solution. Bioinformatics 2018, 34, 1287-1294. [CrossRef]

47. Anderson, M.J. A new method for non-parametric multivariate analysis of variance. Austral Ecol. 2001, 26, 32-46. [CrossRef]

48. Martin, M. Cutadapt removes adapter sequences from high-throughput sequencing reads. EMBnet. J. 2011, 17, 10-12. [CrossRef]

49. Bolger, A.M.; Lohse, M.; Usadel, B. Trimmomatic: A flexible trimmer for Illumina Sequence Data. Bioinformatics 2014, 30, 2114-2120. [CrossRef]

50. Peng, Y.; Leung, H.C.; Yiu, S.M.; Chin, F.Y. IDBA-UD: A de novo assembler for single-cell and metagenomic sequencing data with highly uneven depth. Bioinformatics 2012, 28, 1420-1428. [CrossRef]

51. Huang, X.; Madan, A. CAP3: A DNA sequence assembly program. Genome Res. 1999, 9, 868-877. [CrossRef]

52. Buchfink, B.; Xie, C.; Huson, D.H. Fast and sensitive protein alignment using DIAMOND. Nat. Methods 2015, 12, 59-60. [CrossRef] 
53. De Castro, E.; Sigrist, C.J.A.; Gattiker, A.; Bulliard, V.; Langendijk-Genevaux, P.S.; Gasteiger, E.; Bairoch, A.; Hulo, N. ScanProsite: Detection of PROSITE signature matches and ProRule-associated functional and structural residues in proteins. Nucleic Acids Res. 2006, 34, W362-W365. [CrossRef]

54. Sigrist, C.J.A.; de Castro, E.; Cerutti, L.; Cuche, B.A.; Hulo, N.; Bridge, A.; Bougueleret, L.; Xenarios, I. New and continuing developments at PROSITE. Nucleic Acids Res. 2013, 41, D344-D347. [CrossRef]

55. Kumar, S.; Stecher, G.; Li, M.; Knyaz, C.; Tamura, K. MEGA X: Molecular evolutionary genetics analysis across computing platforms. Mol. Biol Evol. 2018, 35, 1547-1549. [CrossRef] [PubMed]

56. Waterhouse, A.; Bertoni, M.; Bienert, S.; Studer, G.; Tauriello, G.; Gumienny, R.; Heer, F.T.; de Beer, T.A.P.; Rempfer, C.; Bordoli, L.; et al. SWISS-MODEL: Homology modelling of protein structures and complexes. Nucleic Acids Res. 2018, 46, W296-W303. [CrossRef]

57. Steentoft, C.; Vakhrushev, S.Y.; Joshi, H.J.; Kong, Y.; Vester-Christensen, M.B.; Schjoldager, K.T.; Lavrsen, K.; Dabelsteen, S.; Pedersen, N.B.; Marcos-Silva, L.; et al. Precision mapping of the human O-GalNAc glycoproteome through SimpleCell technology. EMBO J. 2013, 32, 1478-1488. [CrossRef] [PubMed]

58. Fernández-Fueyo, E.; Linde, D.; Almendral, D.; Lopez-Lucendo, M.F.; Ruiz Dueñas, F.J.; Martínez, A.T. Description of the first fungal dye-decolorizing peroxidase oxidizing manganese (II). Appl. Microbiol. Biotechnol. 2015, 99, 8927-8942. [CrossRef] [PubMed]

59. Kolwek, J.; Behrens, C.; Linke, D.; Krings, U.; Berger, R.G. Cell-free one-pot conversion of (+) -valencene to (+) -nootkatone by a unique dye-decolorizing peroxidase combined with a laccase from Funalia trogii. J. Ind. Microbiol. Biotechnol. 2018, 45, 89-101. [CrossRef] [PubMed]

60. Kung, C.P.; Wu, Y.R.; Chuang, H.W. Expression of a dye-decolorizing peroxidase results in hypersensitive response to cadmium stress through reducing the ROS signal in Arabidopsis. Environ. Exp. Bot. 2014, 101, 47. [CrossRef]

61. Linde, D.; Ruiz-Dueñas, F.J.; Fernández-Fueyo, E.; Guallar, V.; Hammel, K.E.; Pogni, R.; Martínez, A.T. Basidiomycete DyPs: Genomic diversity, structural-functional aspects, reaction mechanism and environmental significance. Arch. Biochem. Biophys. 2015, 574, 66-74. [CrossRef] [PubMed]

62. Johjima, T.; Ohkuma, M.; Kudo, T. Isolation and cDNA cloning of novel hydrogen peroxide-dependent phenol oxidase from the basidiomycete Termitomyces albuminosus. Appl. Microbiol. Biotechnol. 2003, 61, 220-225. [CrossRef] [PubMed]

63. Scheibner, M.; Hulsdau, B.; Zelena, K.; Nimtz, M.; de Boer, L.; Berger, R.G.; Zorn, H. Novel peroxidases of Marasmius scorodonius degrade b-carotene. Appl. Microbiol. Biotechnol. 2008, 77, 1241-1250. [CrossRef] [PubMed]

64. Zelena, K.; Zorn, H.; Nimtz, M.; Berger, R.G. Heterologous expression of the msp2 gene from Marasmius scorodonius. Arch. Microbiol. 2009, 191, 397-402. [CrossRef] [PubMed]

65. Salvachúa, D.; Prieto, A.; Martínez, Á.T.; Martínez, M.J. Characterization of a novel dye-decolorizing peroxidase (DyP)-type enzyme from Irpex lacteus and its application in enzymatic hydrolysis of wheat straw. Appl. Environ. Microbiol. 2013, 79, 4316-4324. [CrossRef]

66. Lauber, C.; Schwarz, T.; Quoc, K.N.; Lorenz, P.; Lochnit, G.; Zorn, H. Identification, heterologous expression and characterization of a dye-decolorizing peroxidase of Pleurotus sapidus. AMB Express 2017, 7. [CrossRef] [PubMed]

67. Colpa, D.I.; Fraaije, M.W.; van Bloois, E. DyP-type peroxidases: A promising and versatile class of enzymes. J. Ind. Microb. Biotechnol. 2014, 41, 1-7. [CrossRef] [PubMed]

68. Sáez-Jiménez, V.; Baratto, M.C.; Pogni, R.; Rencoret, J.; Gutiérrez, A.; Santos, J.I.; Martínez, A.T.; Ruiz-Dueñas, F.J. Demonstration of lignin-to-peroxidase direct electron transfer: A transient-state kinetics, directed mutagenesis, EPR and NMR study. J. Biol. Chem. 2015, 290, 23201-23213. [CrossRef]

69. Zerva, A.; Christakopoulos, P.; Topakas, E. Characterization and application of a novel class II thermophilic peroxidase from Myceliophthora thermophila in biosynthesis of polycatechol. Enzym. Microb. Technol. 2015, 75, 49-56. [CrossRef] [PubMed]

70. Chalak, A.; Villares, A.; Moreau, C.; Haon, M.; Grisel, S.; d'Orlando, A.; Herpoël-Gimbert, I.; Labourel, A.; Cathala, B.; Berrin, J.G. Influence of the carbohydrate-binding module on the activity of a fungal AA9 lytic polysaccharide monooxygenase on cellulosic substrates. Biotechnol. Biofuels 2019, 12, 1-10. [CrossRef] [PubMed]

71. Valderrama, B.; Ayala, M.; Vazquez-Duhalt, R. Suicide inactivation of peroxidases and the challenge of engineering more robust enzymes. Chem Biol. 2002, 9, 555-565. [CrossRef]

72. Bouillon, S.; Borges, A.; Castañeda-Moya, E.; Diele, K.; Dittmar, T.; saraDuke, N.; Kristensen, E.; Lee, S.; Marchand, C.; Middelburg, J.; et al. Mangrove Production and Carbon sinks: A revision of global budget estimates. Glob. Biogeochem. Cycles 2008, 22, 1-12. [CrossRef]

73. Saravanakumar, K.; Anburaj, R.; Gomathi, V.; Kandasamy, K. Ecology of soil microbes in a tropical mangrove forest of south east coast of India. Biocatal Agric. Biotechnol. 2016, 8, 73-85. [CrossRef]

74. Lombard, V.; Golaconda Ramulu, H.; Drula, E.; Coutinho, P.M.; Henrissat, B. The Carbohydrate-active enzymes database (CAZy) in 2013. Nucleic Acids Res. 2014, 42, D490-D495. [CrossRef]

75. Barbi, F.; Prudent, E.; Vallon, L.; Buée, M.; Dubost, A.; Legout, A.; Marneisse, R.; Fraissinet-Tachet, L.; Luis, P. Tree species select diverse soil fungal communities expressing different sets of lignocellulolytic enzyme-encoding genes. Soil Biol. Biochem. 2016, 100, 149-159. [CrossRef] 
76. Deborde, J.; Marchand, C.; Molnar, N.; Patrona, L.D.; Meziane, T. Concentrations and fractionation of carbon, iron, sulfur, nitrogen and phosphorus in mangrove sediments along an intertidal gradient (semi-arid climate, New Caledonia). J. Mar. Sci. Eng. 2015, 3, 52-72. [CrossRef]

77. Molnar, N.; Marchand, C.; Deborde, J.; Patrona, L.C.; Meziane, T. Seasonal pattern of the biogeochemical properties of mangrove sediments receiving shrimp farm effluents (New Caledonia). J. Aquacult Res. Dev. 2014, 05, 1-13. [CrossRef]

78. Leopold, A.; Marchand, C.; Renchon, A.; Deborde, J.; Quiniou, T.; Allenbach, M. Net ecosystem $\mathrm{CO}_{2}$ exchange in the “Coeur de Voh" mangrove, New Caledonia: Effects of water stress on mangrove productivity in a semi-arid climate. Agric. For. Meteorol. 2016, 223, 217-232. [CrossRef]

79. Alongi, D.M.; Clough, B.F.; Robertson, A.I. Nutrientuse efficiency in arid-zone forests of the mangroves Rhizophora stylosa and Avicennia marina. Aquat. Bot. 2005, 82, 121-131. [CrossRef]

80. Thiem, D.; Gołębiewski, M.; Hulisz, P.; Piernik, A.; Hrynkiewicz, K. How does salinity shape bacterial and fungal microbiomes of Alnus glutinosa roots? Front. Microbiol. 2018, 9, 651. [CrossRef]

81. Ruiz-Dueñas, F.J.; Pogni, R.; Morales, M.; Giansanti, S.; Mate, M.J.; Romero, A.; Martínez, M.J.; Basosi, R.; Martínez, A.T. Protein radicals in fungal versatile peroxidase: Catalytic tryptophan radical in both Compound I and Compound II and studies on W164Y, W164H and W164S variants. J. Biol. Chem. 2009, 284, 7986-7994. [CrossRef] [PubMed]

82. Smith, A.T.; Doyle, W.A.; Dorlet, P.; Ivancich, A. Spectroscopic evidence for an engineered, catalytically active Trp radical that creates the unique reactivity of lignin peroxidase. Proc. Nat. Acad. Sci. USA 2009, 106, 16084-16089. [CrossRef]

83. Miki, Y.; Calviño, F.R.; Pogni, R.; Giansanti, S.; Ruiz-Dueñas, F.J.; Martínez, M.J.; Basosi, R.; Romero, A.; Martínez, A.T. Crystallographic, kinetic, and spectroscopic study of the first ligninolytic peroxidase presenting a catalytic tyrosine. J. Biol. Chem. 2011, 286, 15525-15534. [CrossRef]

84. Adnan, L.A.; Yusoff, A.R.M.; Hadibarata, T.; Khudhair, A.B. Biodegradation of bis-azo dye Reactive Black 5 by white-rot fungus Trametes gibbosa sp. WRF 3 and its metabolite characterization. Water Air Soil Pollut. 2014, 225, 2119. [CrossRef]

85. Hadibarata, T.; Adnan, L.A.; Yusoff, A.R.M.; Yuniarto, A.; Zubir, M.M.F.A.; Khudhair, A.B.; Teh, Z.C.; Naser, M.A. Microbial decolorization of an azo dye reactive black 5 using white-rot fungus Pleurotus eryngii F032. Water Air Soil Pollut. 2013, $224,1595$. [CrossRef]

86. Kim, S.J.; Ishikawa, K.; Hirai, M.; Shoda, M. Characteristics of a newly isolated fungus, Geotrichum candidum Dec 1 , which decolorizes various dyes. J. Ferment Bioeng. 1995, 79, 601-607. [CrossRef]

87. Hanapi, S.Z.; Abdelgalil, S.A.; Hatti-Kaul, R.; Aziz, R.; El Enshasy, H.A. Isolation of a new efficient dye decolorizing white rot fungus Cerrena Sp. WICC F39. J. Sci. Ind. Res. 2018, 77, 399-404.

88. Park, C.; Lim, J.S.; Lee, Y.; Lee, B.; Kim, S.W.; Lee, J.; Kim, S. Optimization and morphology for decolorization of reactive black 5 by Funalia trogii. Enzym. Microb. Technol. 2007, 40, 1758-1764. [CrossRef]

89. Husain, Q. Immobilized Peroxidase Catalyzed Decolorization and Degradation of Industrially Important Dyes from Polluted Water Salt-responsive lytic polysaccharide monooxygenases from the mangrove fungus Pestalotiopsis sp. NCi6. Biocatal. Springer Cham. 2019, 139-166. [CrossRef]

90. Patel, I.; Kracher, D.; Ma, S.; Garajova, S.; Haon, M.; Faulds, C.B.; Berrin, J.G.; Ludwig, R.; Record, E. Salt-responsive lytic polysaccharide monooxygenases from the mangrove fungus Pestalotiopsis sp. NCi6. Biotechnol. Biofuels 2016, 9, 108. [CrossRef]

91. Kern, M.; McGeehan, J.E.; Streeter, S.D.; Martin, R.N.A.; Besser, K.; Elias, L.; Eborall, W.; Malyon, G.P.; Payne, C.M.; Himmel, M.E.; et al. Structural characterization of a unique marine animal family 7 cellobiohydrolase suggests a mechanism of cellulase salt tolerance. Proc. Nat. Acad Sci. USA 2013, 110, 10189-10194. [CrossRef]

92. Paul, S.; Bag, S.K.; Das, S.; Harvill, E.T.; Dutta, C. Molecular signature of hypersaline adaptation: Insights from genome and proteome composition of halophilic prokaryotes. Genome Biol. 2008, 9, R70. [CrossRef] [PubMed]

93. Lanyi, J.K. Salt-dependent properties of proteins from extremely halophilic bacteria. Bacteriol. Rev. 1974, 38, 272-290. [CrossRef] [PubMed] 